\title{
Hydrogen-Air Mixing Evaluation in Reciprocating Engines
}

\section{Dodge \\ D. Naegeli}

Southwest Research Institute

San Antonio, Texas

NREL technical monitor: C. Colucci

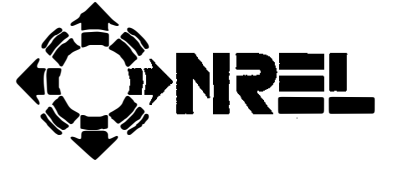

National Renewable Energy Laboratory 1617 Cole Boulevard Golden, Colorado 80401-3393

A national laboratory of the U.S. Department of Energy Operated by Midwest Research Institute for the U.S. Department of Energy

Under Contract No. DE-AC02-83CH10093

Prepared under Subcontract No. AW-2-12266-1

June 1994 


\section{NOTICE}

NOTICE: This report was prepared as an account of work sponsored by an agency of the United States government. Neither the United States government nor any agency thereof, nor any of their employees, makes any warranty, express or implied, or assumes any legal liability or responsibility for the accuracy, completeness, or usefulness of any information, apparatus, product, or process disclosed, or represents that its use would not infringe privately owned rights. Reference herein to any specific commercial product, process, or service by trade name, trademark, manufacturer, or otherwise does not necessarily constitute or imply its endorsement, recommendation, or favoring by the United States government or any agency thereof. The views and opinions of authors expressed herein do not necessarily state or reflect those of the United States government or any agency thereof.

\section{Printed in the United States of America \\ Available from:}

National Technical Information Service

U.S. Department of Commerce

$$
\begin{aligned}
& 5285 \text { Port Royal Road } \\
& \text { Springfield, VA } 22161 \\
& \text { Price: Microfiche A01 }
\end{aligned}
$$

Printed Copy $\mathrm{AO3}$

Codes are used for pricing all publications. The code is determined by the number of pages in the publication. Information pertaining to the pricing codes can be found in the current issue of the following publications which are generally available in most libraries: Energy Research Abstracts (ERA); Government Reports Announcements and Index (GRA and I); Scientific and Technical Abstract Reports (STAR); and publication NTIS-PR-360 available from NTIS at the above address. 


\section{Preface}

This work was conducted by Southwest Research Institute (SwRI), San Antonio, Texas, under Subcontract No. AW-2-12266-1, Prime Contract No. DE-AC02-83CH10093, SwRI Project No. 03-5299 for the National Renewable Energy Laboratory (NREL), Golden, Colorado, and the U.S. Department of Energy (DOE), Washington, D.C. The contributions of technical monitors Brent K. Bailey and Christopher P. Colucci of NREL, John A. Russell of DOE, and subcontract administrator Ernest G. Oster of NREL are gratefully acknowledged. Further, contributions from the Musashi Institute of Technology (Musashi I.T.) in Tokyo, Japan, were essential to the conduct of Task 3, Hydrogen-Air Mixing Evaluation. The contributions of Katsuyoshi Koyanagi, Kimitaka Yamane, and Shoichi Furuhama are gratefully acknowledged. Susuma Ariga of SwRI helped to make the interaction with Musashi I.T. possible. Douglas Leone is greatly appreciated for his help in setting up the personal computer version of ChemkinII, which was used in the chemical kinetics modeling work in Task 2. The patience and expertise of Ms. Janie Gonzalez in preparing this report are appreciated.

This effort consisted of three fairly autonomous tasks. The first task addressed cold-starting problems in alcohol-fueled, spark-ignition engines by using fine-spray port-fuel injectors to inject fuel directly into the cylinder. This task included development and characterization of some very fine-spray, port-fuel injectors for a methanol-fueled spark-ignition engine. After determining the spray characteristics, a computational study was performed to estimate the evaporation rate of the methanol fuel spray under cold-starting conditions and steady-state conditions. The second task was to perform a fundamental kinetic study of the autoignition characteristics of methylal, an oxygenated fuel that produces almost no soot in diesel engines, but, in contrast with most oxygenated fuels, has an excellent cetane number. The third task was to perform a computational study of fuel-air mixing in a hydrogen jet using a spark-ignited, hydrogenfueled engine. The computational results were compared with experimental measurements being conducted at Musashi I.T. The hydrogen-air mixing work was directed at understanding the extreme sensitivity of ignition to spark plug location and spark timing in direct-injected, hydrogen-fueled engines.

The third task is covered in this report. Tasks 1 and 2 are discussed in NREL reports TP-425-6344 and TP-425-6345, respectively. 


\section{Executive Summary}

An essential part of this effort was for SwRI personnel to become familiar with the progress made in hydrogen fuel use in internal combustion engines through research conducted at the Musashi Institute of Technology (Musashi I.T.) over the past 20 or more years. Visits by SwRI personnel to Musashi I.T. in Tokyo, and vice versa, accomplished the goal of sharing experience with hydrogen fuels.

The general shape of the hydrogen-air (actually hydrogen-nitrogen) mixing as measured by Rayleigh lightscattering measurements was predicted by the JETMIX model, including both axial and radial variations. However, the predicted hydrogen concentrations were greater than the measured values, and the width of the computed hydrogen-nitrogen plume, based on schlieren photography, was greater than the width measured by Rayleigh light scattering. These observations suggest some shortcomings with the model's ability to predict experimental results, as well as inconsistencies in the experimental results. The experimental measurements of hydrogen concentration suggest a significantly narrower jet width than that inferred from schlieren photographs. Transient effects of hydrogen jet propagation through the 17-mm distance between the injector valve and injector tip are not handled properly in the JETMIX model, which was developed for a diesel-type injector where the valve is very close to the injector tip.

A number of suggestions have been developed during this study to address the extreme sensitivity of the spark-ignition event in hydrogen-fueled engines. Perhaps some of these suggestions may be implemented in future engine tests. 


\section{Contents}

\section{Page}

Background $\ldots \ldots \ldots \ldots \ldots \ldots \ldots \ldots \ldots \ldots \ldots \ldots \ldots \ldots \ldots \ldots \ldots$

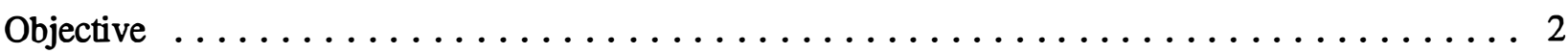

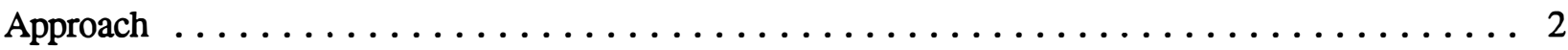

Experimental Measurements $\ldots \ldots \ldots \ldots \ldots \ldots \ldots \ldots \ldots \ldots \ldots \ldots \ldots \ldots \ldots \ldots$

Jet-Mixing Model $\ldots \ldots \ldots \ldots \ldots \ldots \ldots \ldots \ldots \ldots \ldots \ldots \ldots \ldots \ldots \ldots$

Comparison of Calculations and Measurements for Hydrogen-Air Mixing $\ldots \ldots \ldots \ldots$

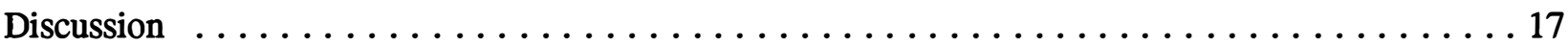

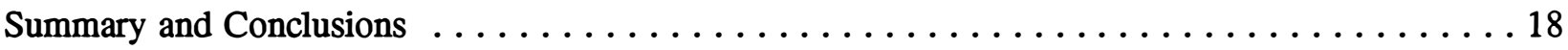

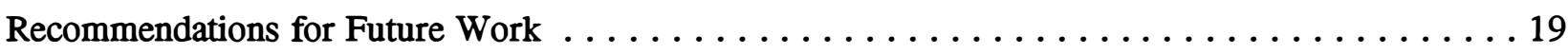

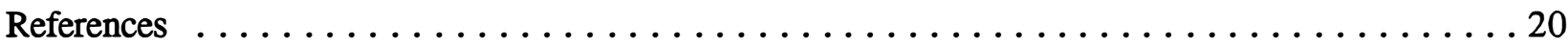

Appendix A Equations for Conservation of Jet Momentum Rate and Fuel Mass Flux in Free Jet and Wall Jet . . . . . . . . . . . . . . A-1 


\section{List of Figures}

Figure

$\underline{\text { Page }}$

1 Typical profiles of fuel-air concentration expressed in terms of equivalence ratio for gaseous fuel injected through a simple hole-type injector, where an equivalence ratio of 1.0 represents a chemically correct, or

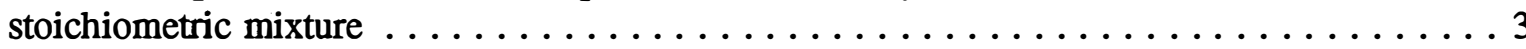

2(a) Straight-tip hydrogen-injection nozzle used in Musashi I.T. tests $\ldots \ldots \ldots \ldots \ldots$

2(b) Expanded-tip hydrogen-injection nozzle used in Musashi I.T. tests $\ldots \ldots \ldots \ldots \ldots \ldots$

3 High-pressure bomb used for hydrogen injector tests at Musashi I.T. $\ldots \ldots \ldots \ldots$

4 Optical set-up used for hydrogen concentration measurements at Musashi I.T. . . . . . 6

5 Examples of signals from hydrogen concentration measurements at Musashi I.T. . . . . 8

6 Comparison of predicted (by JETMIX) and measured hydrogen fuel concentrations in a hydrogen-nitrogen jet for straight injector tip

$5 \mathrm{~mm}$ downstream of the injector tip. $\mathrm{P}_{\text {inj. }}=2.94 \mathrm{MPA}, \mathrm{P}_{\text {chem. }}=0.98 \mathrm{MPa} \ldots \ldots \ldots 11$

7 Comparison of predicted (by JETMIX) and measured hydrogen fuel concentrations in a hydrogen-nitrogen jet for straight injector tip $10 \mathrm{~mm}$ downstream of the injector tip, $\mathrm{P}_{\text {inj. }}=2.94 \mathrm{MPa}, \mathrm{P}_{\text {chem. }}=0.98 \mathrm{MPa} \ldots \ldots \ldots \ldots \ldots$

8 Comparison of predicted (by JETMIX) and measured hydrogen fuel concentrations in a hydrogen-nitrogen jet for straight injector tip $15 \mathrm{~mm}$ downstream of the injector tip, $P_{\text {inj. }}=2.94 \mathrm{MPa}, \mathrm{P}_{\text {chem. }}=0.98 \mathrm{MPa} \ldots \ldots \ldots \ldots$

9 Comparison of predicted (by JETMIX) and measured hydrogen fuel concentrations in a hydrogen-nitrogen jet for straight injector tip $20 \mathrm{~mm}$ downstream of the injector tip, $P_{\text {inj. }}=2.94 \mathrm{MPa}, \mathrm{P}_{\text {chem. }}=0.98 \mathrm{MPa} \ldots \ldots \ldots \ldots$

10 Comparison of predicted (by JETMIX) and measured hydrogen fuel concentrations in a hydrogen-nitrogen jet for straight injector tip $5 \mathrm{~mm}$ downstream of the injector tip, $\mathrm{P}_{\text {inj. }}=2.94 \mathrm{MPa}, \mathrm{P}_{\text {chem. }}=0.98 \mathrm{MPa} \ldots \ldots \ldots \ldots \ldots$

11 Comparison of predicted (by JETMIX) and measured hydrogen fuel concentrations in a hydrogen-nitrogen jet for straight injector tip $10 \mathrm{~mm}$ downstream of the injector tip, $P_{\text {inj. }}=2.94 \mathrm{MPa}, \mathrm{P}_{\text {chem. }}=0.98 \mathrm{MPa} \ldots \ldots \ldots \ldots$

12 Comparison of predicted (by JETMIX) and measured hydrogen fuel concentrations in a hydrogen-nitrogen jet for straight injector tip $15 \mathrm{~mm}$ downstream of the injector tip, $P_{\text {inj. }}=2.94 \mathrm{MPa}, \mathrm{P}_{\text {chem. }}=0.98 \mathrm{MPa} \ldots \ldots \ldots$

13 Comparison of predicted (by JETMIX) and measured hydrogen fuel concentrations in a hydrogen-nitrogen jet for straight injector tip $20 \mathrm{~mm}$ downstream of the injector tip, $\mathrm{P}_{\text {inj. }}=2.94 \mathrm{MPa}, \mathrm{P}_{\text {chem. }}=0.98 \mathrm{MPa} \ldots \ldots \ldots \ldots$ 


\section{List of Figures \\ (Concluded)}

Figure

$\underline{\text { Page }}$

14 Comparison of predicted and measured hydrogen-nitrogen jet from straight-tip injector, $\mathrm{P}_{\text {inj. }}=1.86 \mathrm{MPA}, \mathrm{P}_{\text {chem. }}=1.08 \mathrm{MPa} \ldots \ldots \ldots \ldots \ldots \ldots \ldots \ldots \ldots \ldots \ldots \ldots \ldots \ldots \ldots$

15 Comparison of predicted and measured hydrogen-nitrogen jet from straight-tip injector, $\mathrm{P}_{\text {inj. }}=2.45 \mathrm{MPA}, \mathrm{P}_{\text {chem. }}=1.08 \mathrm{MPa} \ldots \ldots \ldots \ldots \ldots \ldots \ldots \ldots \ldots \ldots \ldots \ldots \ldots \ldots \ldots$

16 Comparison of predicted and measured hydrogen-nitrogen jet from straight-tip

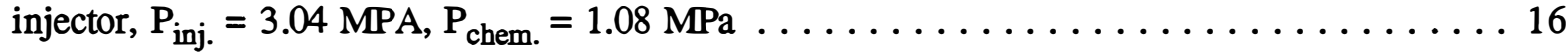

17 Comparison of predicted and measured hydrogen-nitrogen jet from straight-tip injector, $\mathrm{P}_{\text {inj. }}=3.82 \mathrm{MPA}, \mathrm{P}_{\text {chem. }}=1.08 \mathrm{MPa} \ldots \ldots \ldots \ldots \ldots \ldots \ldots \ldots \ldots \ldots \ldots \ldots \ldots \ldots \ldots$ 


\section{Hydrogen-Air Mixing Evaluation in Reciprocating Engines}

\section{Background}

Hydrogen-fueled engines are attractive power sources that do not produce greenhouse gases $\left(\mathrm{CO}_{2}\right)$, with the exception of burned oil and carbon monoxide (CO). The exhaust products are nitrogen $\left(\mathrm{N}_{2}\right)$, water vapor $\left(\mathrm{H}_{2} \mathrm{O}\right)$, and nitric oxide (NO). Of these, only nitric oxide is considered a problem. Hydrogen can be burned in internal-combustion engines in various ways. Because it has a high autoignition temperature, it is more attractive as a fuel for spark-ignition engines than for compression-ignition engines.

The hydrogen fuel-air formation for a spark-ignited engine can be mixed external to the cylinder or in the cylinder. Mixing in-cylinder can be either early injection, which forms a homogeneous charge, or late injection (near top-dead-center, TDC) so that the fuel burns as it is injected, as in a diesel engine. External mixing of hydrogen and air is limited both by the power that can be produced and by backfiring through the intake system. The power limitation is due to air being displaced by hydrogen gas. Because the air/fuel ratio for a stoichiometric mixture of hydrogen is 2.4 by volume, the maximum air flow into the engine is reduced by about $29 \%$ relative to injection of the fuel into the cylinder, reducing the maximum engine power by a similar amount. Backfiring associated with external mixing of the fuel occurs when pre-ignition of the fuel advances at every cycle until it finally occurs before the intake valve is closed, causing the flame to propagate into the premixed charge in the intake system and explode (Furuhama 1992). One approach to avoiding backfire is to make the hydrogen-air mixture lean to slow the flame speed; this results in a practical limit of about $50 \%$ of the power available from stoichiometric combustion of hydrogen in the same-size engine (Furuhama 1992). External mixing can result in very high efficiencies under lean operation, but is limited in maximum power.

There are two choices for in-cylinder injection of hydrogen: (1) early-cycle, low-pressure injection forming a pre-mixed charge, or (2) late-cycle, high-pressure injection (near TDC). The early-cycle injection is limited by pre-ignition from hot surfaces and by knocking due to the very high flame speed of hydrogen $(320 \mathrm{~cm} / \mathrm{s}$ for rich mixtures versus $45 \mathrm{~cm} / \mathrm{s}$ for most hydrocarbon fuels; Glassman 1987). This results in erratic combustion and limits the power available. The pre-ignition problem may be somewhat reduced by injecting cooled hydrogen gas, but this approach appears to be more effective for 2-stroke engines than for 4-stroke engines (Furuhama 1992).

Late-cycle injection of hydrogen overcomes the pre-ignition problem if the fuel can be ignited early in the injection process and then burned as it is injected. However, the ignition and burning can be very rough if the ignition timing does not allow combustion to occur very early in the injection process (Furuhama 1992; Koyanagi et al. 1993). Very careful control of spark timing and location can help control the erratic combustion. Also, late-cycle injection requires high injection pressures to overcome the high cylinder pressures, with injection pressures of about $1 \mathrm{MPa}$ (Koyanagi et al. 1993). This latecycle, high-pressure hydrogen injection may be more easily controlled and more practical using liquid hydrogen rather than gaseous hydrogen. Musashi Institute of Technology (Musashi I.T.), Tokyo, Japan, has developed liquid-hydrogen storage and high-pressure liquid pumps and injection systems suitable for automobiles and has used them on several demonstration vehicles (Furuhama and Tomisawa 1991). Storing liquid hydrogen on vehicles reduces the weight requirements (Furuhama 1991). However, it is a very low-temperature cryogenic fuel, and that, of course, introduces a number of handling and storage problems.

In addition to the requirement for developing cryogenic fuel pumping and handling systems, late-cycle, direct-injection of hydrogen has been limited by the extreme sensitivity to spark timing and location (Furuhama 1992; Koyanagi et al. 1993). Hydrogen has several properties that must be considered in evaluating this problem. First, it has very wide flammability limits, making it easier to locate the spark 
in a combustible portion of the fuel-air plume, an asset when compared with gasoline. However, because the fuel is gaseous rather than liquid when it is injected, there is no liquid evaporation to limit the burning rate. Further, for stoichiometric mixtures, the laminar flame speed of hydrogen is about four times that of gasoline. Thus, if a significant amount of hydrogen has been sprayed into the cylinder before ignition, the initial combustion rate is so great that maximum cylinder pressures are exceeded. Therefore, the spark must occur early in the injection process, before much hydrogen has been injected. This means that the spark plug must be located close to the fuel injector, and the mixture must be ignited before very much fuel-air mixing has occurred. Figure 1 shows a contour plot of gaseous fuel-air mixing ratios, expressed in terms of stoichiometry, where 1.0 is the "chemically correct" mixture. Note that, close to the injector, the gradients in fuel-air ratio are very high, making it very difficult to select a spark-plug location that is at a mixture ratio where ignition is easily achievable, especially considering the fact that engine swirl will deflect the fuel plume and that changing engine speeds will cause different amounts of deflection. This was the problem addressed in this project: to evaluate hydrogen-air mixing in a direct-injection engine, early in the injection process.

\section{Objective}

The objective of this work was to evaluate hydrogen fuel-air mixing in a direct-injection system for a spark-ignited, hydrogen-fueled vehicle, especially early in the injection process. The purpose of this work was to gain sufficient understanding of the problem of erratic combustion of hydrogen to determine what approaches might be tried to more easily ignite the hydrogen-air plume in the engine. The computational portion of this work was performed at SwRI, San Antonio, Texas, while the experimental portion was conducted at Musashi I.T. in Tokyo. This NREL/DOE contract sponsored the work conducted at SwRI only.

\section{Approach}

Experimental measurements of hydrogen-air (actually nitrogen in place of air) mixing in a hydrogen-fuel, direct-injection system were conducted at Musashi I.T. These experiments included measurements of hydrogen fuel concentration by Rayleigh light scattering of hydrogen and nitrogen (the background gas in the bomb), and by high-speed schlieren photographs of penetration rates of hydrogen gas into a nitrogen-filled bomb. The Rayleigh light-scattering measurements gave a determination of relative molecular concentration of hydrogen and nitrogen. The molecular concentration ratios are the same as the ratios by volume of the two gases, so these ratios can be compared directly with ratios computed by the model. The penetration rates also may be compared with penetration estimates made by the model.

The experimental measurements of hydrogen-air mixing from Musashi I.T. tests were compared with computational estimates of mixing using the JETMIX computer model, a model previously developed at SwRI for diesel fuel studies. Specifying the cone angle of the fuel-air jet from experimental measurements, and the fuel pressure and hole size of the injector hole, the fuel-air mixing of a steady-state gas jet can be predicted in a two-dimensional plane. The two dimensions are the axial distance from the injector tip and the radial distance from the centerline of the jet. The transient penetration rate can be estimated as a fraction of the steady-state penetration of a parcel of fuel on the centerline of the steadystate jet. 


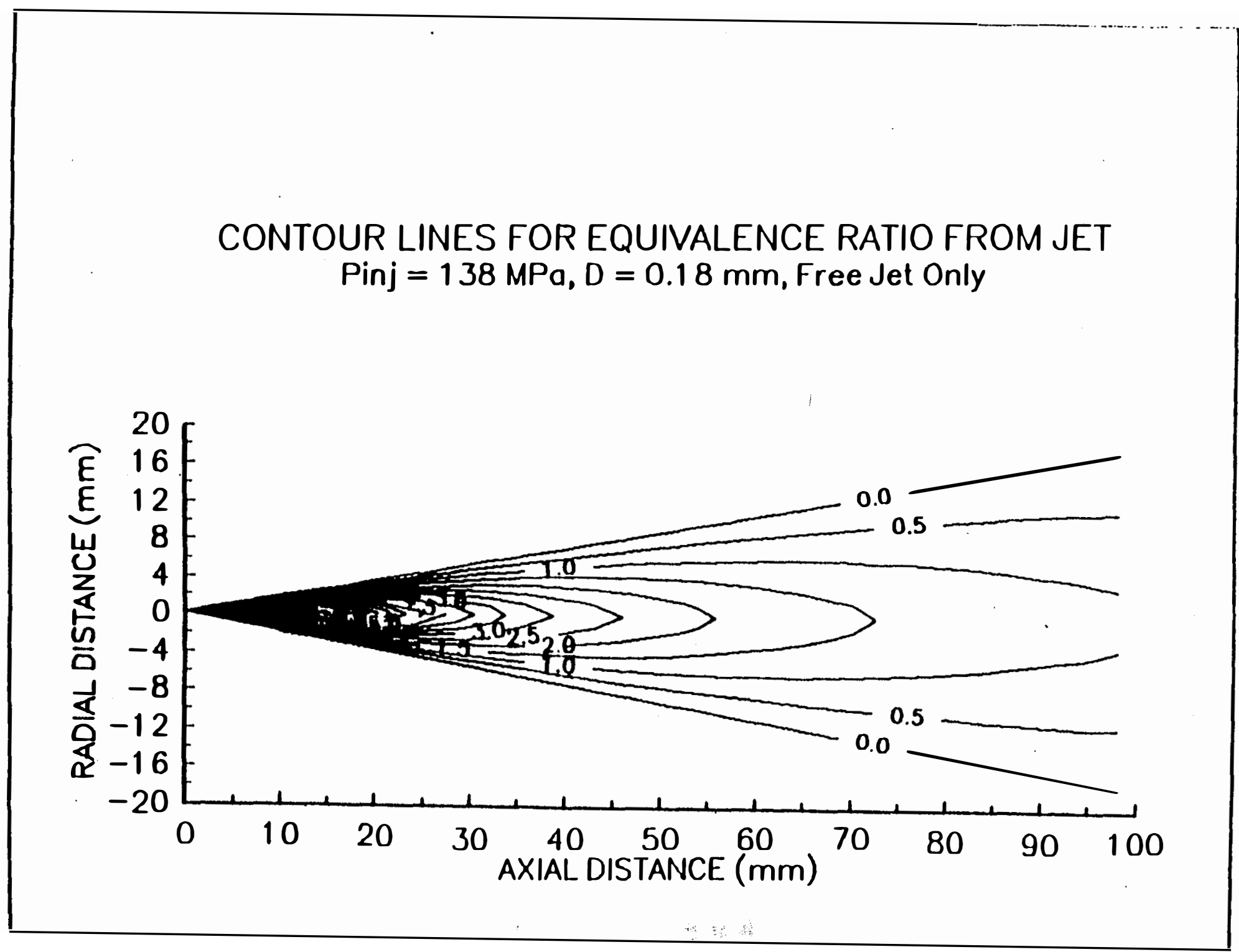

Figure 1. Typical profiles of fuet-air concentration expressed in terms of equivalence ratio for gaseous fuel injected through a simple hole-type injector, where an equivalence ratio of 1.0 represents a chemically correct, or stoichiometric mixture. 


\section{Experimental Measurements}

All experimental measurements were conducted at Musashi I.T. by K. Koyanagi, under the direction of $\mathrm{K}$. Yamane and S. Furuhama and colleagues. These experiments were not funded by NREL. A complete description of the experimental apparatus and results is beyond the scope of this project. However, some background information has been provided by $\mathrm{K}$. Koyanagi and is included here. Two hydrogen injector tips were characterized for hydrogen concentration downstream of the tips. The standard or straight tip is shown in Figure 2(a), and the expanded tip is shown in Figure 2(b). In both cases, the valve is located $17 \mathrm{~mm}$ upstream of the injector tip. The injector tip being tested was mounted in an elevated-pressure, room-temperature bomb as shown in Figure 3. The optical apparatus for making the Rayleigh scattering measurements of hydrogen concentration is shown in Figure 4. High-speed schlieren photography was used for penetration-rate measurements on the standard injector tip.

The hydrogen concentration measurements were based on Rayleigh scattering measurements, which measure molecular scattering. Hydrogen was injected into a nitrogen-filled bomb. As the hydrogen displaced some of the nitrogen, the scattering intensity was reduced since the smaller hydrogen molecule has a smaller Rayleigh scattering cross-section than the nitrogen molecule. The general expression for the scattering intensity is

$$
\mathrm{I}=\mathrm{CI}_{0} \mathrm{~N} \sigma
$$

where $\mathrm{I}$ is the scattering intensity in mks units of watts $\mathrm{m}^{-2}$; $\mathrm{C}$ is a constant for the optical system, essentially an effective path length, with dimensions $\mathrm{m} ; \mathrm{I}_{0}$ is the laser light intensity incident on the molecule with units of watts $\bullet \mathrm{m}^{-2} ; \mathrm{N}$ is concentration of molecules in molecules $\mathrm{m}^{-3}$; and $\sigma$ is the Rayleigh scattering cross-section in $\mathrm{m}^{2} \cdot$ molecule $^{-1}$.

Thus, for the first experiment when the bomb is filled with just static nitrogen, the scattering intensity for nitrogen, $\mathrm{I}_{\mathrm{N}}$, is

$$
\mathrm{I}_{\mathrm{N}}=\mathrm{CI}_{0} \mathrm{~N}_{\mathrm{a}} \sigma_{\mathrm{N}}
$$

where $\mathrm{N}_{\mathrm{a}}$ is the molecular concentration for the experiment, which is the molecular concentration of nitrogen, and $\sigma_{\mathrm{N}}$ is the Rayleigh scattering cross-section for nitrogen.

For the second experiment, when hydrogen is injected into the nitrogen-filled bomb, the scattering intensity is due to scattering from both nitrogen and hydrogen. Assuming the mole fraction of nitrogen is $\mathrm{f}_{\mathrm{N}}$ and the mole fraction of hydrogen is $\mathrm{f}_{\mathrm{H}}$, the combined scattering intensity for nitrogen plus hydrogen, $\mathrm{I}_{\mathrm{N}+\mathrm{H}}$, is

$$
I_{(N+H)}=C_{0}\left(f_{N} N_{b} \sigma_{N}+f_{H} N_{b} \sigma_{H}\right)
$$

where $f_{N}$ is the mole (or molecular) fraction of nitrogen molecules in the scattering volume, $f_{H}$ is the mole fraction of hydrogen molecules in the scattering volume, $\mathrm{N}_{\mathrm{b}}$ is the total molecular concentration, and $\sigma_{\mathrm{H}}$ is the Rayleigh scattering cross-section for hydrogen. Because $f_{N}+f_{H}=1$ if only nitrogen and hydrogen are present in the bomb, the combined scattering intensity may be written as

$$
\left.\mathrm{I}_{(\mathrm{H}+\mathrm{N})}=\mathrm{CI}_{0} \mathrm{~N}_{\mathrm{b}}\left[\left(1-\mathrm{f}_{\mathrm{H}}\right) \sigma_{\mathrm{N}}+\mathrm{f}_{\mathrm{H}} \sigma_{\mathrm{H}}\right)\right]
$$




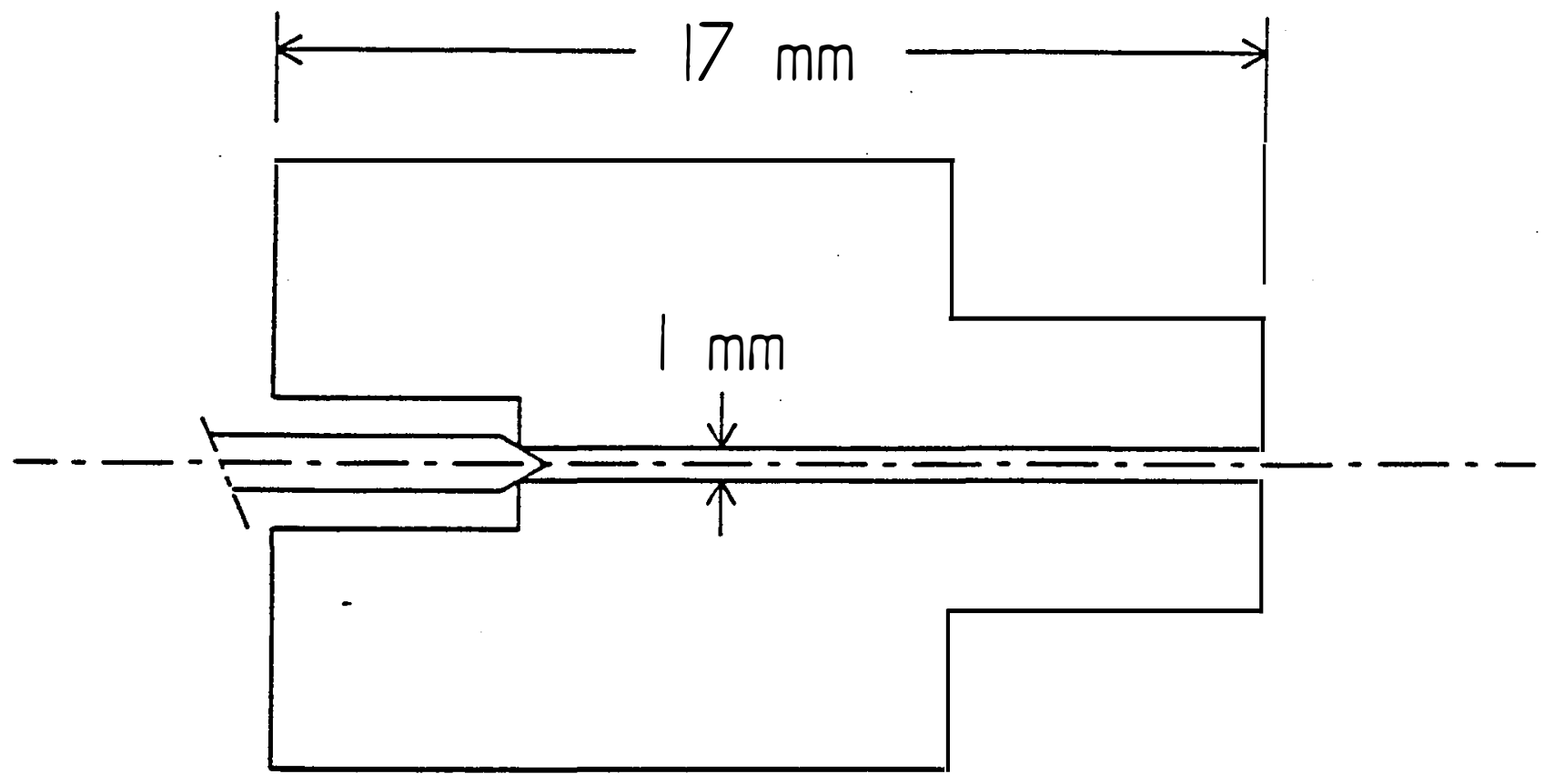

Figure 2(a). Straight-tip hydrogen-injection nozzle used in Musashi I.T. tests.

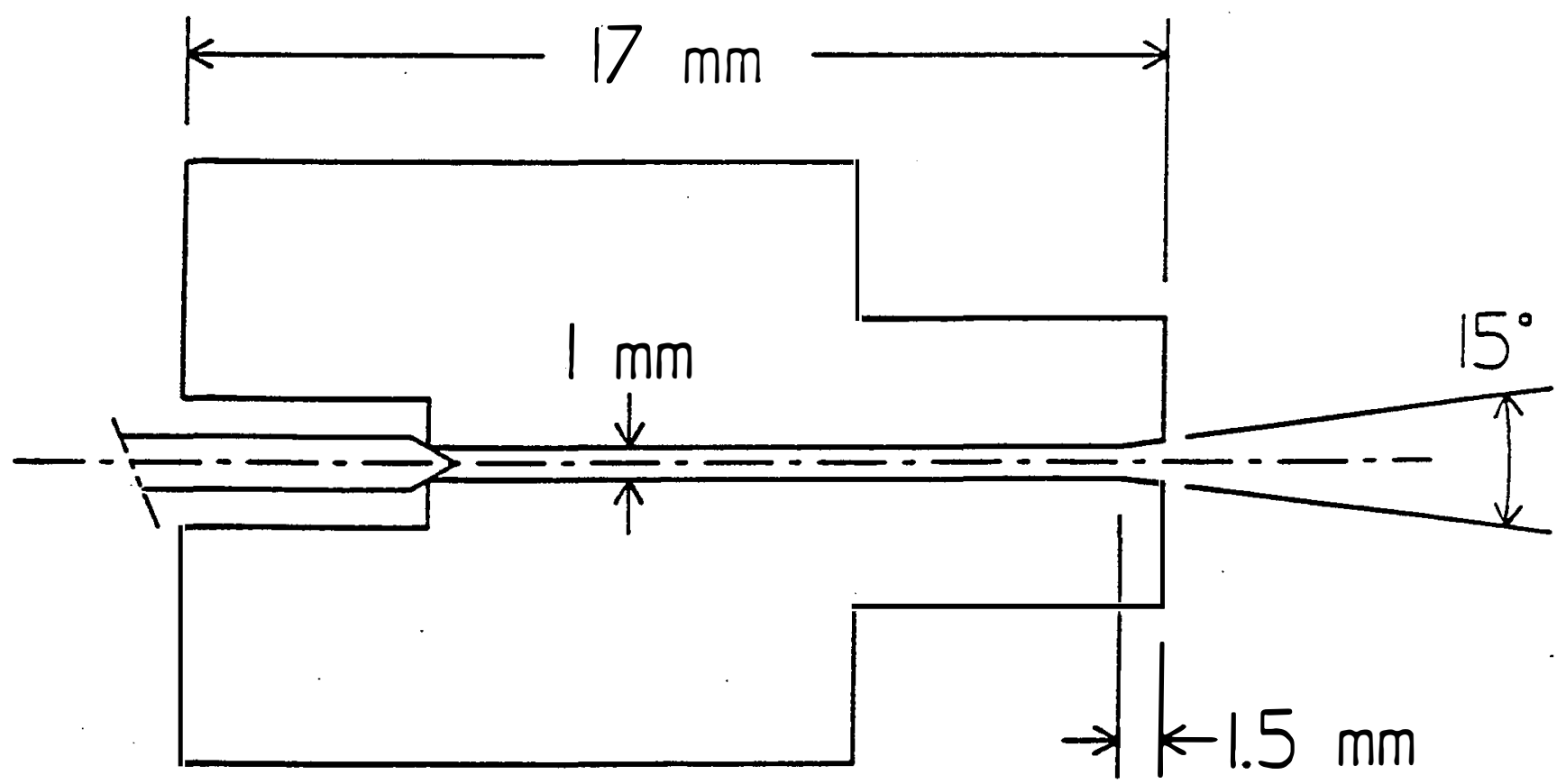

Figure 2(b). Expanded-tip hydrogen-injection nozzle used in Musashi I.T. tests. 


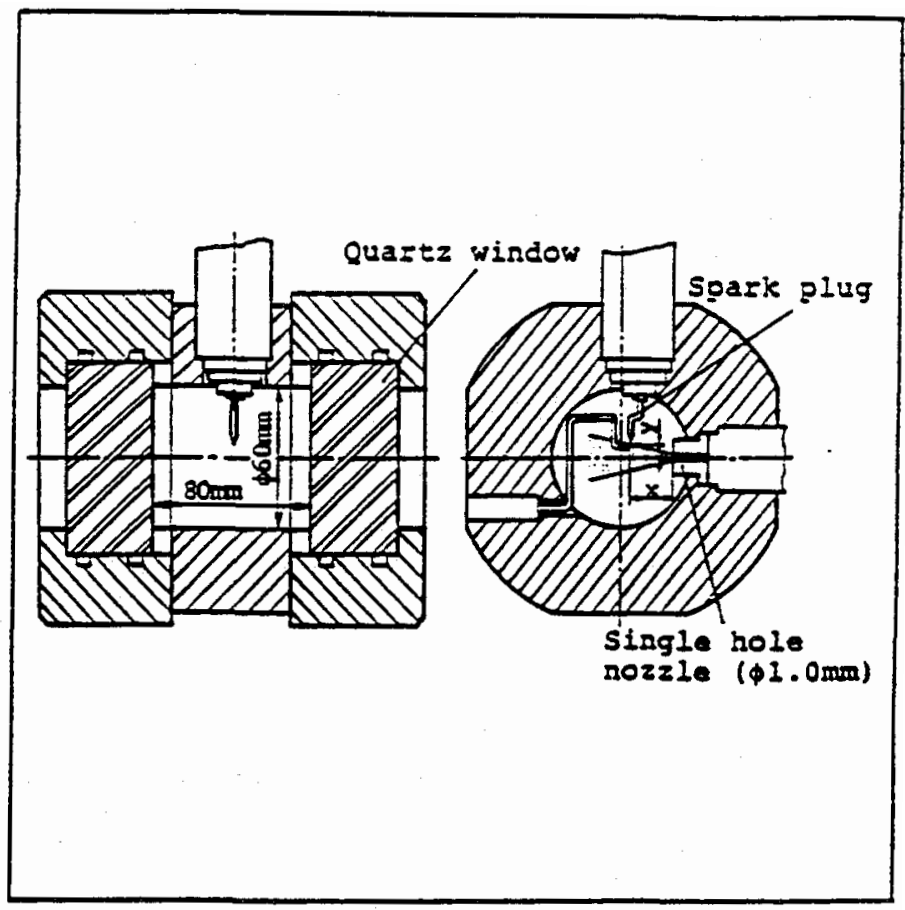

Figure 3. High-pressure bomb used for hydrogen injector tests at Musashi I.T.

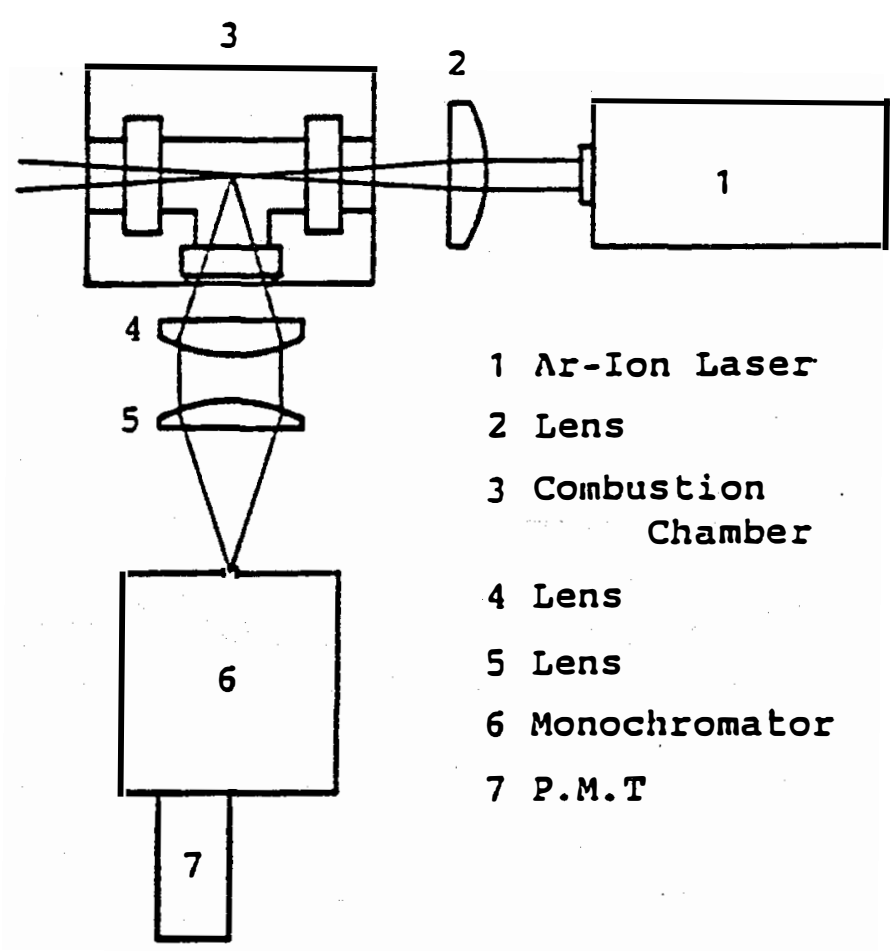

Figure 4. Optical set-up used for hydrogen concentration measurements at Musashi I.T. 
This equation may be solved for the mole fraction of hydrogen as follows

$$
f_{H}=\left(\frac{\sigma_{N}}{\sigma_{H}-\sigma_{n}}\right)\left[\frac{I_{(H+N)}}{C I_{0} N_{b} \sigma_{N}}-1\right]
$$

If the injection of hydrogen does not significantly increase the overall pressure and therefore the molecular density in the bomb, and likewise if the high-velocity jet is assumed to have the same pressure as the stagnant gas in the bomb, ignoring the normal reduction in static pressure and density with velocity, and if the local pressure increase at the head of the penetrating jet is ignored, then $\mathrm{N}_{\mathrm{b}} \approx \mathrm{N}_{\mathrm{a}}$, and

$$
f_{H}=\left(\frac{\sigma_{N}}{\sigma_{H}-\sigma_{n}}\right)\left[\frac{I_{(H+N)}}{I_{N}}-1\right]
$$

Because hydrogen is a smaller molecule than nitrogen, its scattering cross-section $\sigma$ is smaller, and the scattering intensity of the mixture is less than the scattering intensity of nitrogen alone. Some examples of the Rayleigh scattering intensity measurements $5 \mathrm{~mm}$ downstream of the injector tip are shown in Figure 5. Note that scattering intensity actually decreases with increasing hydrogen concentration.

\section{Jet-Mixing Model}

SwRI developed a computer model called JETMIX for evaluating fuel-air mixing in direct-injected, dieselfueled, compression-ignition engines prior to this NREL/DOE project. The JETMIX model simplifies the mixing process by ignoring the phase change of diesel fuel from a liquid to a gas, treating the liquid as a dense gas. This is appropriate since the limit to fuel-air mixing is usually not due to evaporation of the liquid fuel, but to the mixing of the evaporated fuel with the air in the chamber (Heywood 1988). However, this assumption of ignoring the liquid-fuel evaporation is not an issue in the injection of gaseous hydrogen. (The Musashi I.T. design stores and pumps the hydrogen as a cryogenic liquid, then vaporizes it and injects it as a gas.)

The JETMIX model is described in detail in Appendix A as it was developed for diesel injection; some of the modifications required to apply it to hydrogen gas injection are described below. Three assumptions commonly used in the analysis of jets were used to derive the equations used in this model:

(1) The fuel mass-flow rate of the jet at every axial cross-section is the same, and is equal to the fuel mass-flow rate at the source.

(2) The momentum rate of the jet at every cross-section is the same, and is equal to the momentum rate of the jet at the source.

(3) The spreading angle of the jet is assumed to be constant, and the profiles of velocity and fuel mass fraction are assumed to be self-similar and to follow the profiles described in Appendix A.

Appendix A shows how, starting with these assumptions, the fuel-air mixing rate of fuel and air are predicted. However, the appendix illustrates the development of the model for an (approximately) incompressible fluid, diesel fuel. Certain modifications were required to adapt the model to hydrogen. The changes required for hydrogen-air mixing calculations are outlined in this section. 


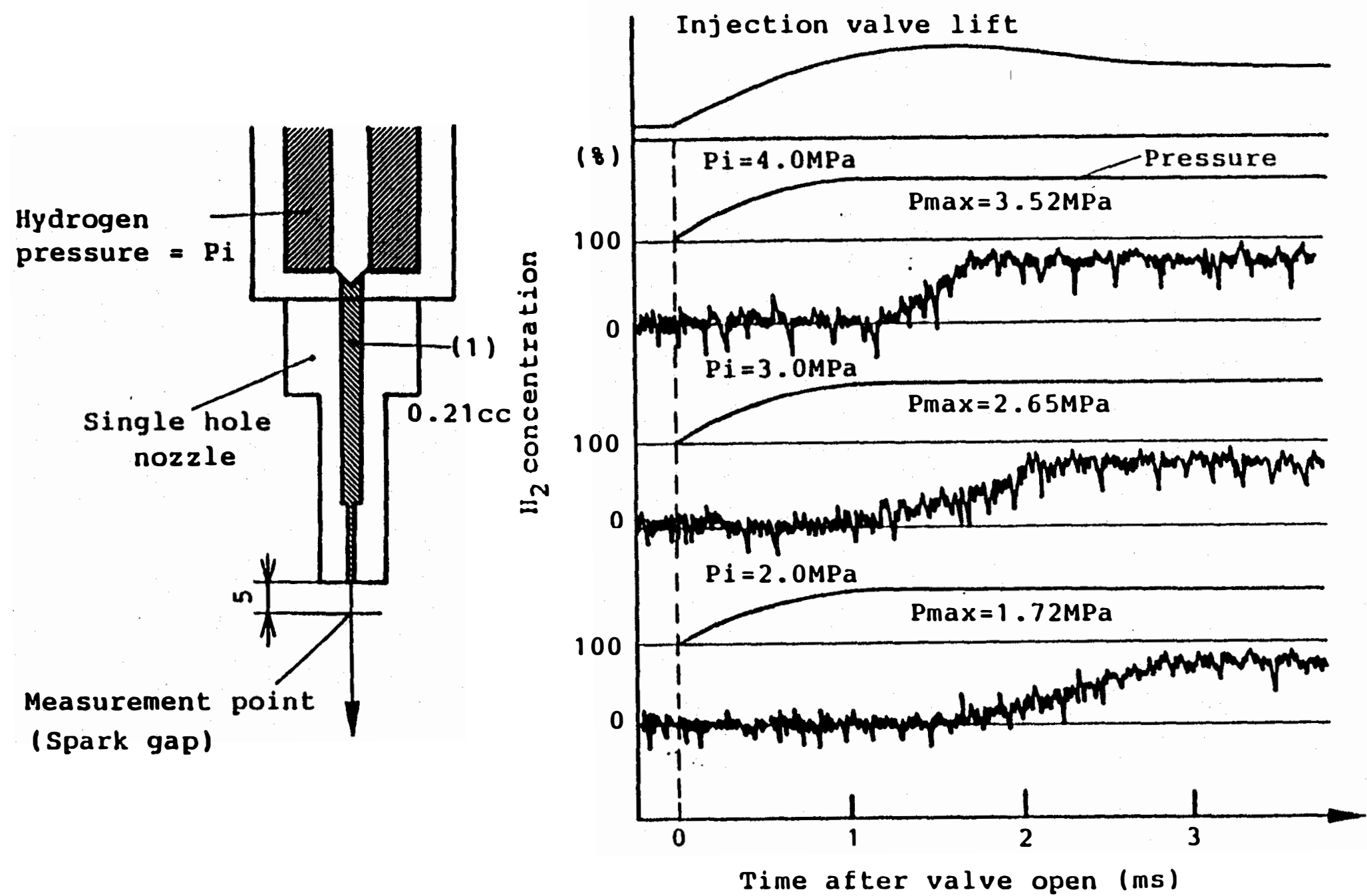

Figure 5. Examples of signals from hydrogen concentration measurements at Musashi I.T. 
The original equations for fuel mass-flow rate and velocity, shown in Appendix A, have been replaced with equations appropriate for compressible gases. The equations used are based on mach number relationships from Shapiro (1953); see especially Equation 4.14b, pg. 83; Equation 4.16, pg. 84; and Equation $4.5 \mathrm{~b}$, pg. 79. In addition to fuel mass fractions that were already calculated, JETMIX was modified to compute fuel volume fractions that can be compared directly with the Rayleigh light-scattering measurements of hydrogen-nitrogen ratios.

The mach number $M$ through the injection nozzle is calculated as

$$
\left.M=\left(\left(\frac{p_{0}}{p}\right)^{\frac{\gamma-1}{\gamma}}-1\right) \frac{2}{\gamma-1}\right)^{1 / 2}
$$

where $\mathrm{p}_{0}$ is the pressure upstream of the injector, $\mathrm{p}$ is the pressure in the bomb, and $\gamma$ is the specific heat ratio. The mach number is converted into a velocity using the sonic velocity, $\mathrm{c}_{0}$, which is

$$
\mathrm{c}_{0}=\sqrt{\gamma \mathrm{RT} / \mathrm{MW}}
$$

where $\mathrm{R}$ is the universal gas constant, $\mathrm{T}$ is the absolute temperature, and $\mathrm{MW}$ is the molecular weight. The gas velocity in the nozzle is estimated from the mach number and the sonic velocity as

$$
\mathrm{V}=\mathrm{c}_{\mathrm{D}} \mathrm{M} \mathrm{c}_{0}
$$

where $c_{D}$ is the discharge coefficient. The fuel mass-flow rate in the injector is calculated as

$$
\dot{\mathrm{m}}=\mathrm{A} \sqrt{\frac{\gamma}{\mathrm{R} / \mathrm{MW}}} \frac{\mathrm{p}_{0}}{\sqrt{\mathrm{T}_{0}}} \frac{\mathrm{M}}{\left(1+\frac{\gamma-1}{2} \mathrm{M}^{2}\right)^{\frac{\gamma+1}{2(\gamma-1)}}}
$$

where $\dot{m}$ is the fuel mass-flow rate and $\mathrm{A}$ is the orifice area.

The JETMIX model was constructed for an almost incompressible fuel, while hydrogen is a compressible gas. Therefore, essentially instantaneous expansion of hydrogen at the exit of the injector must be taken into account. Further, the velocity profile in the injector is assumed to be plug flow with uniform velocity across the orifice, while at the orifice exit the jet must transition into an approximately Gaussian profile.

To address the problem of hydrogen gas expansion, rather than modeling the expansion of the hydrogen gas at the exit from the injector, the gas is assumed to have already expanded in the injector. The density of the hydrogen in the injector is thereby reduced from its actual density by the ratio $\mathrm{p}_{\mathrm{bomb}} / \mathrm{p}_{0}$, where $\mathrm{p}_{\text {bomb }}$ is the background pressure in the bomb and $\mathrm{p}_{0}$ is the pressure upstream of the injector. It is important to maintain the proper mass-flow rate and momentum rate (momentum * velocity) in the injector, so reducing the gas density requires that the area be increased by $\mathrm{p}_{0} / \mathrm{p}_{\text {bomb }}$. The fuel mass-flow rate and the total momentum rate of the jet are constant at every jet cross-section downstream of the injector and are equal to that in the injector. Therefore, both must be correctly specified in the injector. 
To address the rearrangement of the hydrogen-fuel profile from radially uniform in the injector to approximately Gaussian outside the injector, the transition that takes an unknown finite distance in real life is modeled as occurring instantaneously at the nozzle exit. The diameter of the jet must instantaneously increase by a factor of 1.72 to conserve fuel mass for the radial profile of fuel concentration assumed in the model.

Another problem in modeling the gas flow is that, at typical operating conditions, the hydrogen gas velocity in the injector is sonic. For hydrogen at room temperature, this velocity is about $1300 \mathrm{~m} / \mathrm{s}$. As the gas exits the orifice, it accelerates to supersonic and then shocks down to subsonic. However, after air mixes into the jet, sonic velocities are eventually reduced to about $340 \mathrm{~m} / \mathrm{s}$. The jet might continue to further shock to reduce to subsonic velocities relative to air sonic velocities. This might cause some irreversible losses that are not accounted for in the model.

\section{Comparison of Calculations and Measurements for Hydrogen-Air Mixing}

The computer model JETMIX was used to calculate the concentration of hydrogen downstream of two 1-mm diameter injector tips, one with a straight tip, Figure 2(a), and one with an expanded tip, Figure 2(b). The model results were compared with experimental results for hydrogen concentration measured by Rayleigh light scattering and with penetration results measured from schlieren high-speed photography. All experimental results were provided by Musashi I.T.

Comparisons of predicted and measured hydrogen concentrations for the straight tip are provided in Figures 6-9 for axial distances from the injector tip of 5, 10, 15, and $20 \mathrm{~mm}$, respectively. Injection pressure was $2.94 \mathrm{MPa}$, bomb pressure was $0.98 \mathrm{MPa}$, and the orifice was $1 \mathrm{~mm}$ in diameter and $17 \mathrm{~mm}$ long. The cone angle of the jet was fixed at $22^{\circ}$ for these calculations. The mass flow through the injector was measured to be $0.896 \cdot 10^{-3} \mathrm{~kg} / \mathrm{s}\left(630 \mathrm{~N} \mathrm{~L} / \mathrm{min}\right.$, normal conditions being $\left.760 \mathrm{~mm} \mathrm{Hg}, 15^{\circ} \mathrm{C}\right)$. The discharge coefficient in the JETMIX model was adjusted to a value of 0.629 to match the predicted flow rate to the measured value. This is a reasonable discharge coefficient for the sharp-edged, 17-mmlong, 1-mm-diameter orifice. The figures show that the cone angle as measured from the hydrogen concentration measurements was less than $22^{\circ}$. However, the schlieren photographs showed this cone angle to be larger, so $22^{\circ}$ was a compromise. The general development of the jet is well predicted by the model, but the absolute concentrations, or hydrogen-nitrogen ratios, show some discrepancies between experimental measurements and the model. In spite of having a larger computed cone angle, the model predicted higher hydrogen concentrations than were measured. By conservation of mass, the predictions should have been lower than the measured values at centerline if the shapes were broader (larger cone angle).

Similar comparisons for the expanded tip are shown in Figures 10-13 for the expanded-tip hydrogen concentrations at axial distances from the injector tip of 5,10,15, and $20 \mathrm{~mm}$, respectively. Conditions were the same as for the straight tip, except that a cone angle of $33.4^{\circ}$ measured from schlieren photography was used for all computations. Also, the measured mass-flow rate through this injector was $0.931 \cdot 10^{-3} \mathrm{~kg} / \mathrm{s}(655.0 \mathrm{~N} \mathrm{~L} / \mathrm{min})$. The discharge coefficient used in the JETMIX calculations was adjusted to 0.654 so that the computed mass-flow rate agreed with the measured value. Again, the computed hydrogen concentrations in the jet were larger than the measured concentrations, and the cone angle for the computed profiles was broader than for the measured profiles. The computed and measured profiles showed similar shapes and similar evolution moving downstream from the injector tip.

Comparisons of predicted and measured hydrogen jet penetration rates for the straight tip are shown in Figures 14-17 for injection pressures of $1.86,2.45,3.04$, and $3.82 \mathrm{MPa}$, respectively, injecting into the bomb at $1.08 \mathrm{MPa}$. The beginning of injection for the experimental data was somewhat difficult to establish in a format directly comparable with the JETMIX model. The model assumes that the valve 


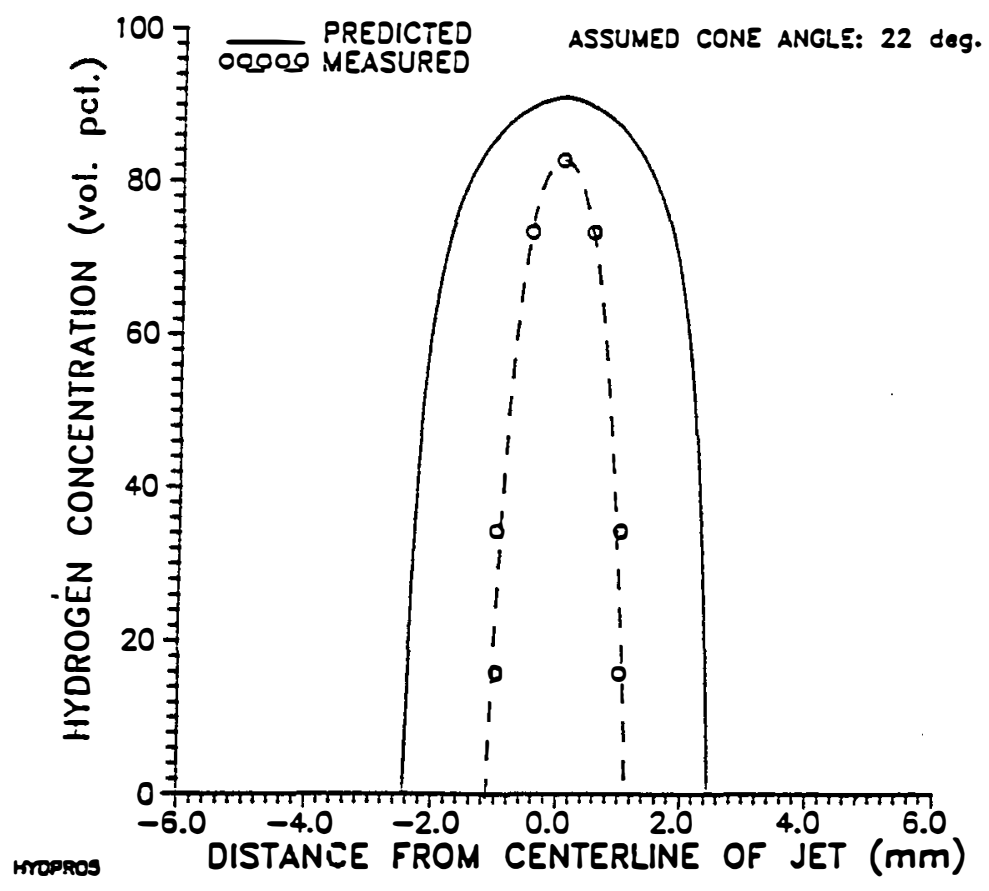

Figure 6. Comparison of predicted (by JETMIX) and measured hydrogen fuel concentrations in a hydrogen-nitrogen jet for straight injector tip $5 \mathrm{~mm}$ downstream of the injector tip. $P_{\text {inj. }}=2.94 \mathrm{MPA}, \mathrm{P}_{\text {chem. }}=0.98 \mathrm{MPa}$.

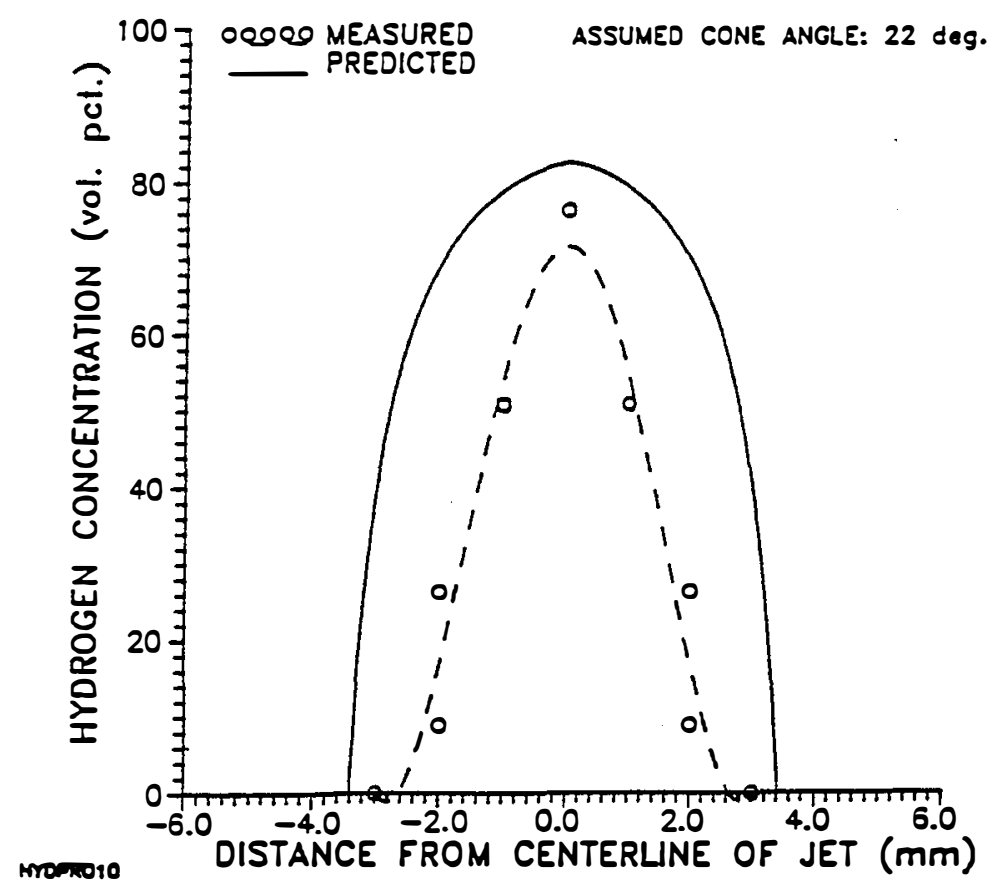

Figure 7. Comparison of predicted (by JETMIX) and measured hydrogen fuel concentrations in a hydrogen-nitrogen jet for straight injector tip $10 \mathrm{~mm}$ downstream of the injector tip, $P_{\text {inj. }}=2.94 \mathrm{MPa}, P_{\text {chem. }}=0.98 \mathrm{MPa}$. 


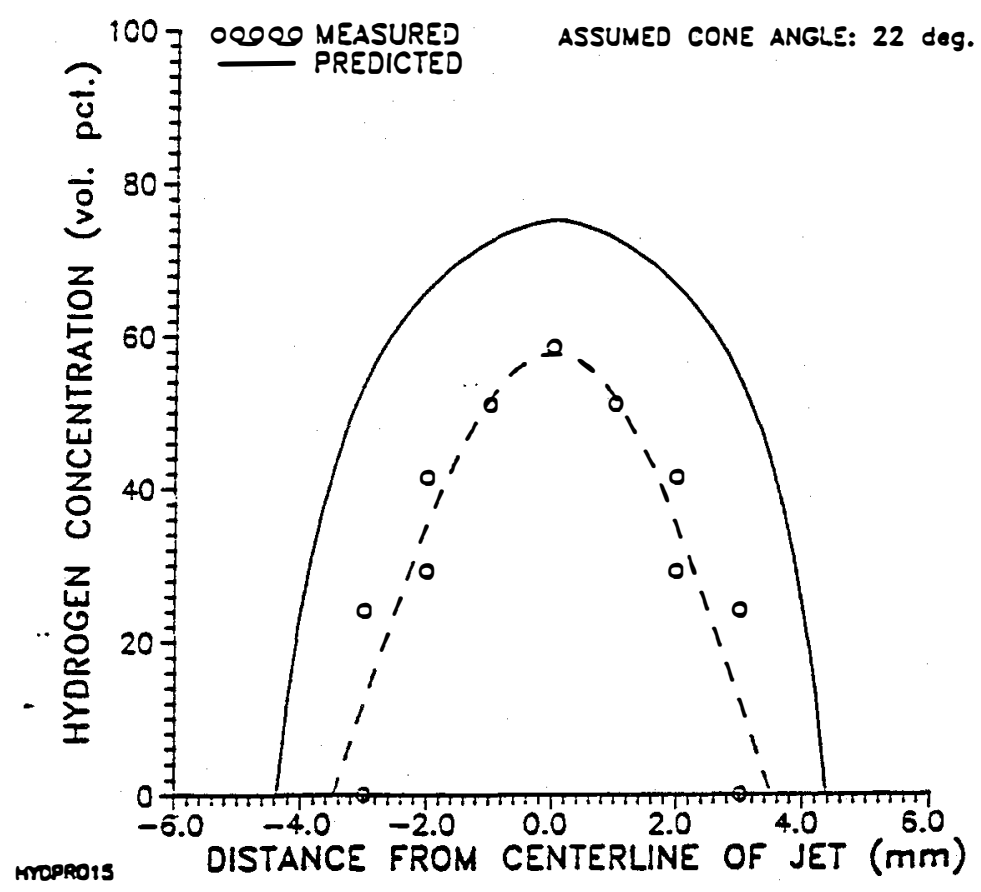

Figure 8. Comparison of predicted (by JETMIX) and measured hydrogen fuel concentrations in a hydrogen-nitrogen jet for straight injector tip $15 \mathrm{~mm}$ downstream of the injector tip, $P_{\text {inj. }}=2.94 \mathrm{MPa}, P_{\text {chem. }}=0.98 \mathrm{MPa}$.

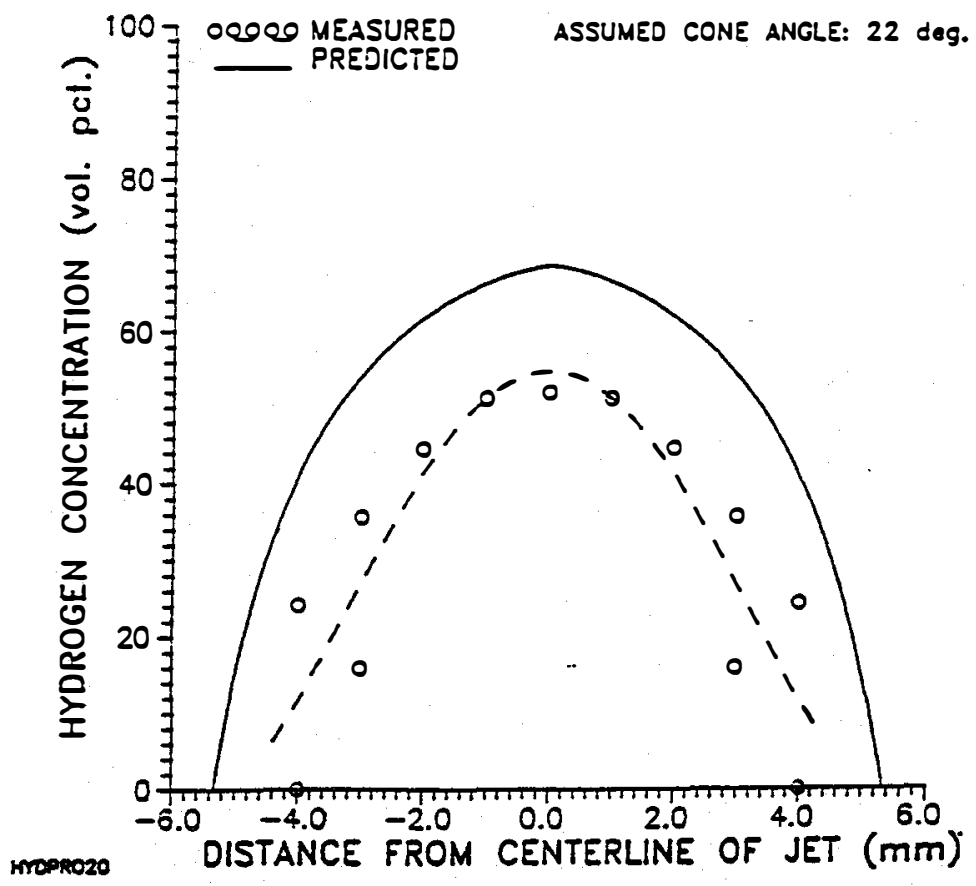

Figure 9. Comparison of predicted (by JETMIX) and measured hydrogen fuel concentrations in a hydrogen-nitrogen jet for straight injector tip $20 \mathrm{~mm}$ downstream of the injector tip, $P_{\text {inj. }}=2.94 \mathrm{MPa}, P_{\text {chem. }}=0.98 \mathrm{MPa}$. 


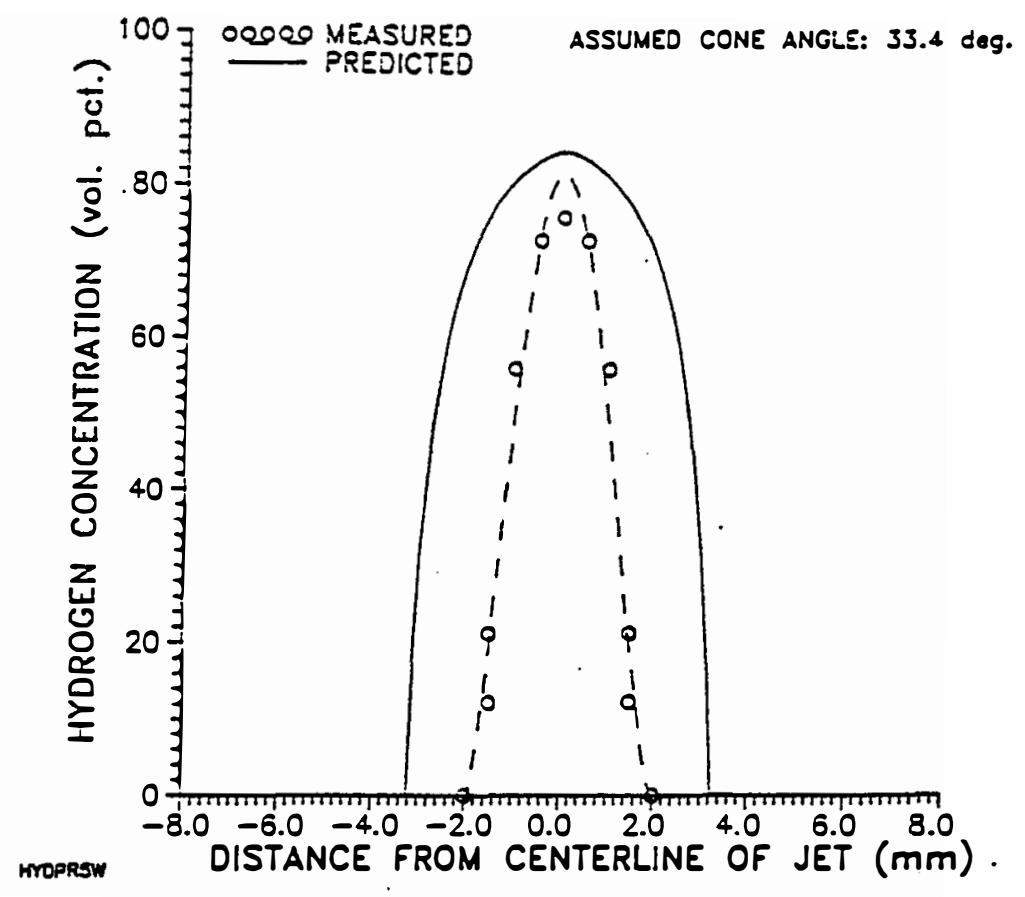

Figure 10. Comparison of predicted (by JETMIX) and measured hydrogen fuel concentrations in a hydrogen-nitrogen jet for straight injector tip $5 \mathrm{~mm}$ downstream of the injector tip, $P_{\text {inj. }}=2.94 \mathrm{MPa}, P_{\text {chem. }}=0.98 \mathrm{MPa}$.

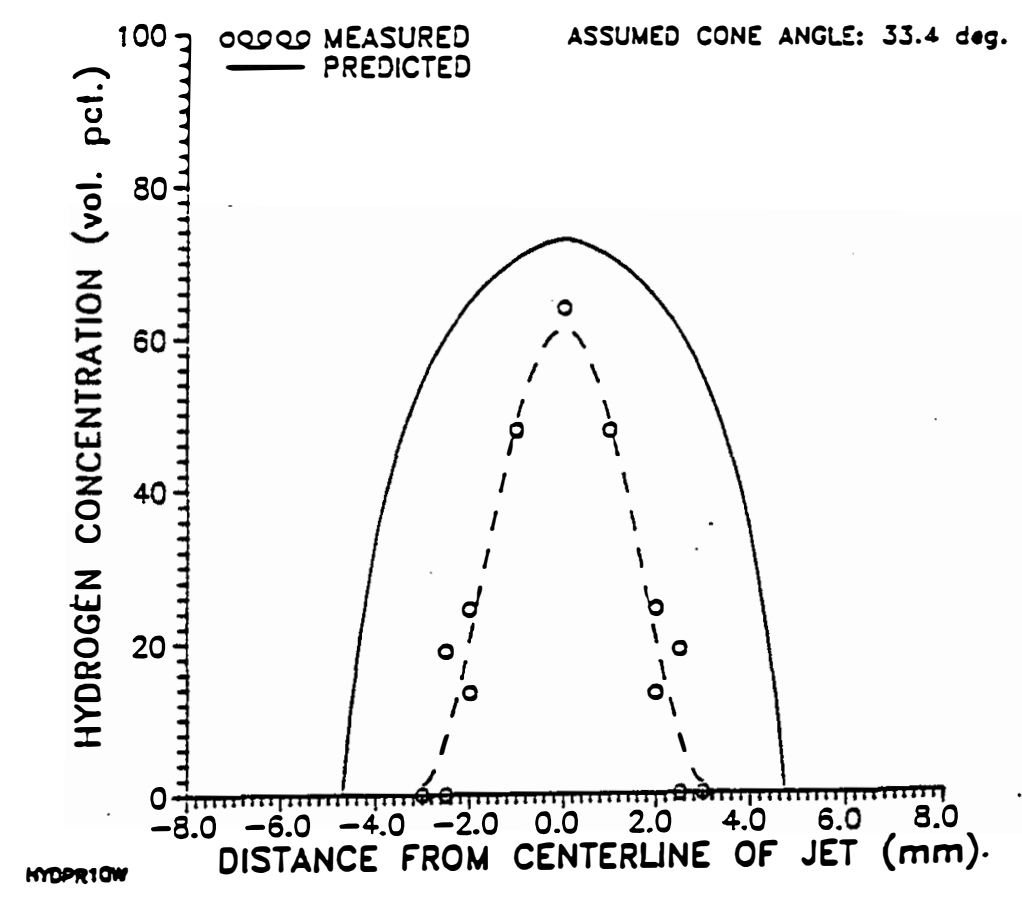

Figure 11. Comparison of predicted (by JETMIX) and measured hydrogen fuel concentrations in a hydrogen-nitrogen jet for straight injector tip $10 \mathrm{~mm}$ downstream of the injector tip, $P_{\text {inj. }}=2.94 \mathrm{MPa}, P_{\text {chem. }}=0.98 \mathrm{MPa}$. 


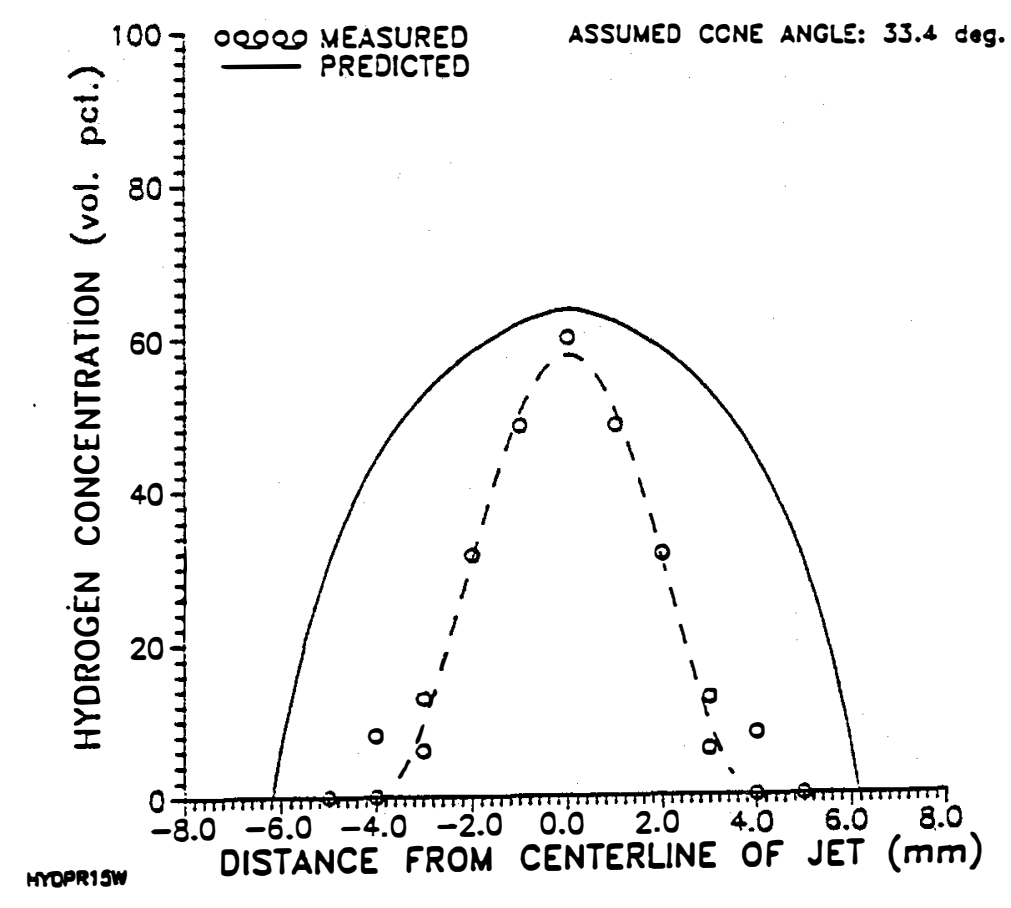

Figure 12. Comparison of predicted (by JETMIX) and measured hydrogen fuel concentrations in a hydrogen-nitrogen jet for straight injector tip $15 \mathrm{~mm}$ downstream of the injector tip, $P_{\text {inj. }}=2.94 \mathrm{MPa}, P_{\text {chem. }}=0.98 \mathrm{MPa}$.

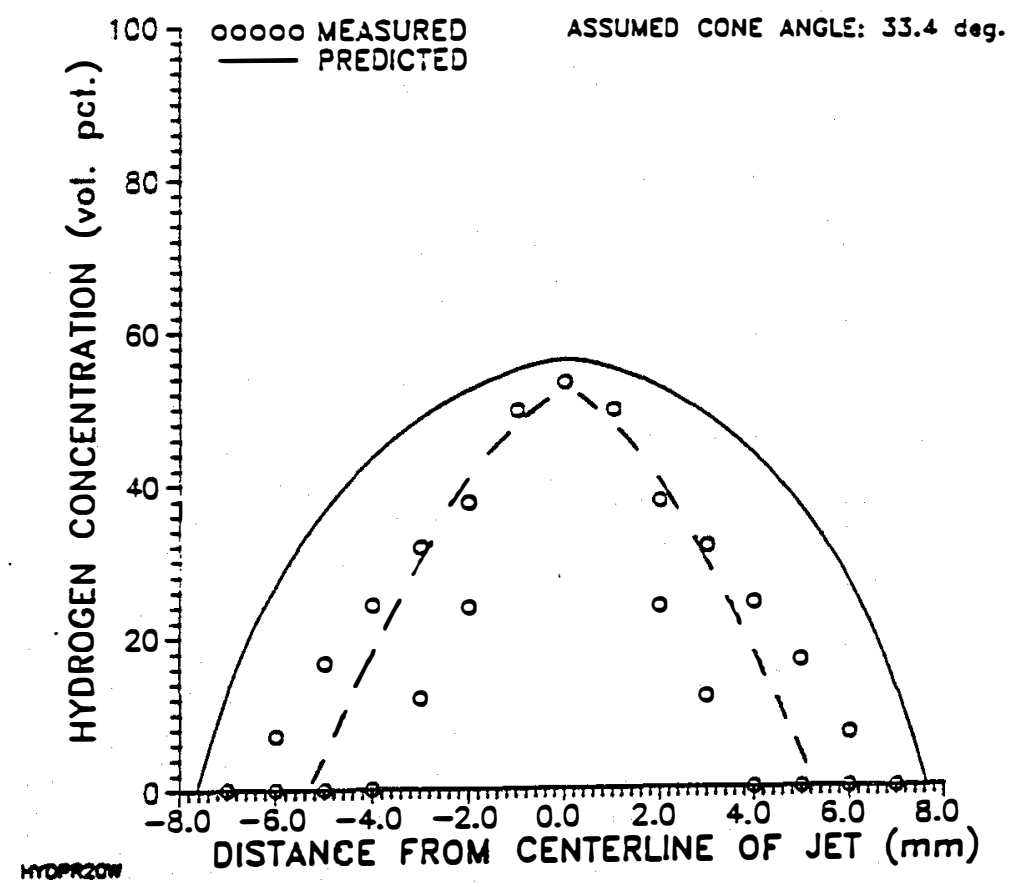

Figure 13. Comparison of predicted (by JETMIX) and measured hydrogen fuel concentrations in a hydrogen-nitrogen jet for straight injector tip $20 \mathrm{~mm}$ downstream of the injector tip, $P_{\text {inj. }}=2.94 \mathrm{MPa}, P_{\text {chem. }}=0.98 \mathrm{MPa}$. 


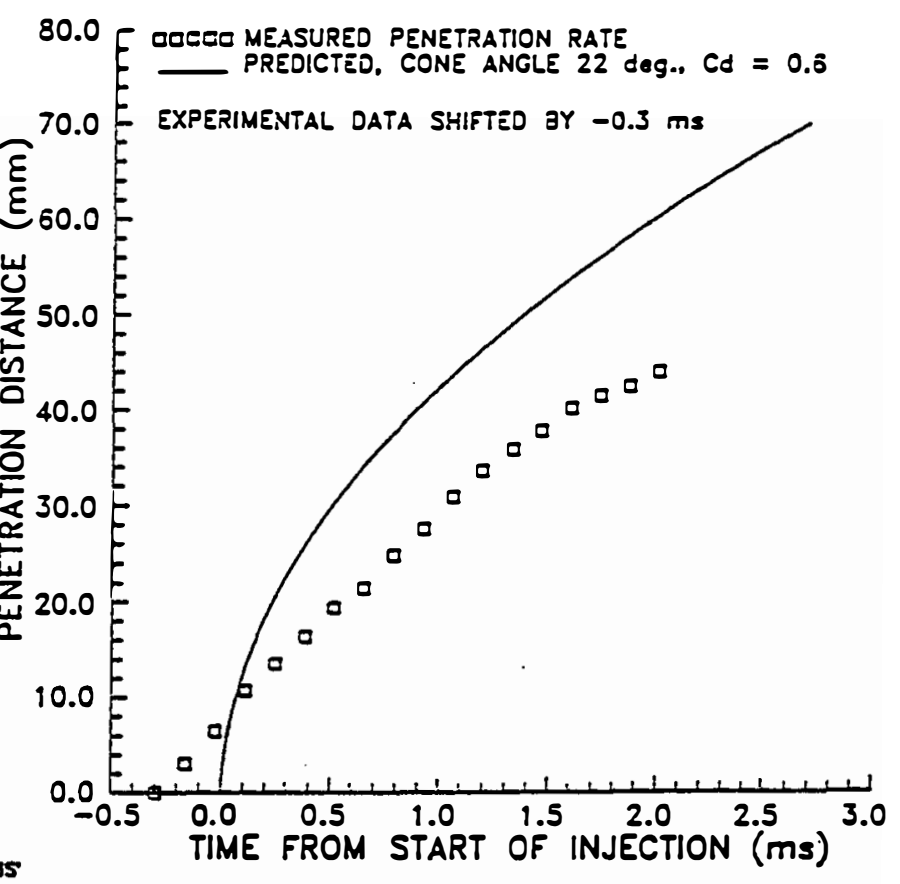

Figure 14. Comparison of predicted and measured hydrogen-nitrogen jet from straight-tip injector, $P_{\text {inj. }}=1.86 \mathrm{MPA}, \mathrm{P}_{\text {chem. }}=1.08 \mathrm{MPa}$.

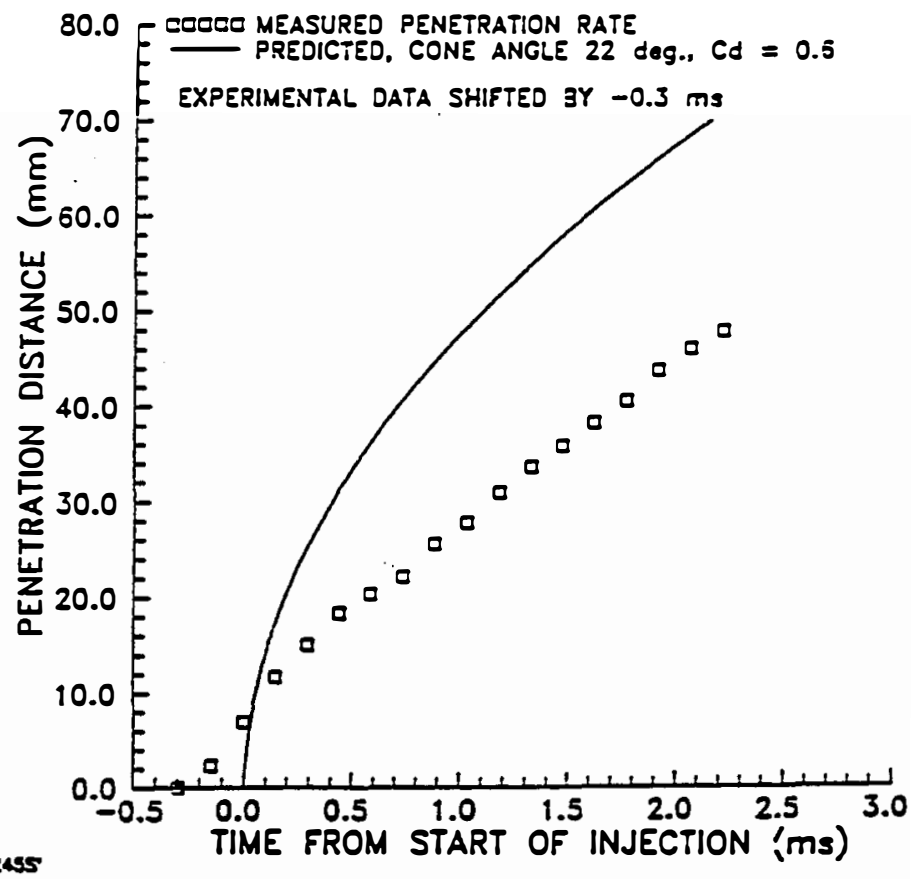

Figure 15. Comparison of predicted and measured hydrogen-nitrogen jet from straight-tip injector, $P_{\text {inj. }}=2.45 \mathrm{MPA}, \mathrm{P}_{\text {chem. }}=1.08 \mathrm{MPa}$. 


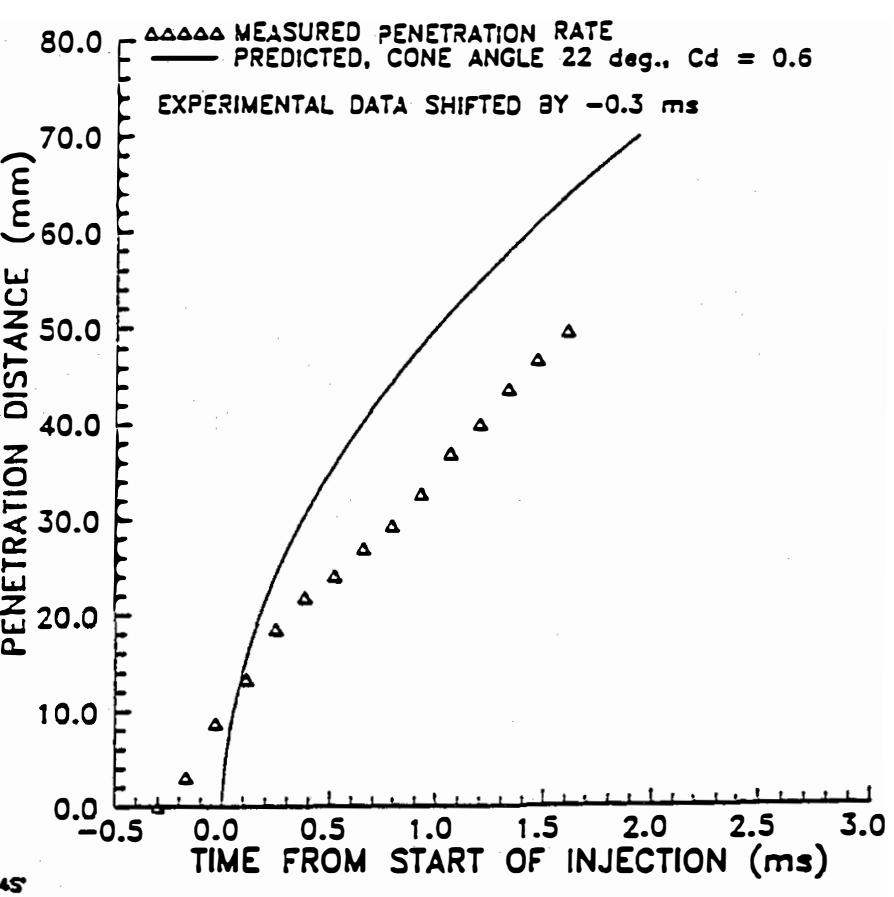

Figure 16. Comparison of predicted and measured hydrogen-nitrogen jet from straight-tip injector, $P_{\text {inj. }}=$ 3.04 MPA, $P_{\text {chem. }}=1.08 \mathrm{MPa}$.

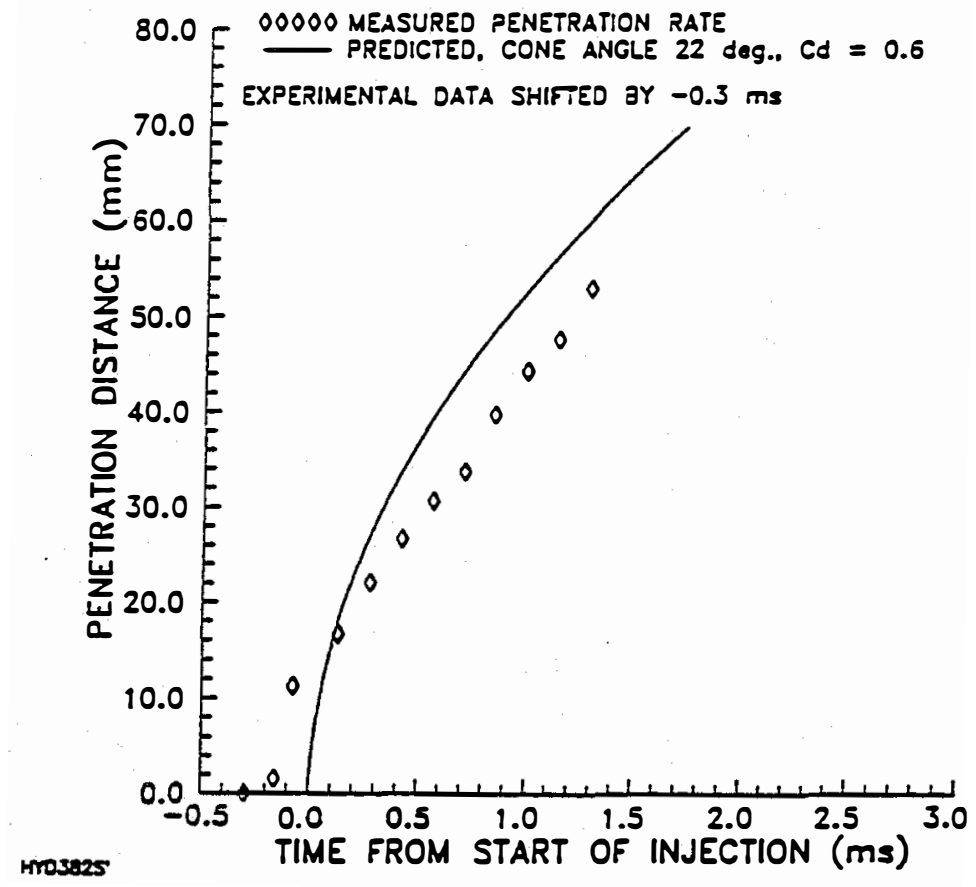

Figure 17. Comparison of predicted and measured hydrogen-nitrogen jet from straight-tip injector, $P_{\text {inj. }}=3.82 \mathrm{MPA}, \mathrm{P}_{\text {chem. }}=1.08 \mathrm{MPa}$. 
controlling the fuel flow is just upstream of the injector holes, as is the case in diesel injectors. However, for these experiments, the control valve was followed by a 17-mm-long, 1-mm-diameter injection tube, as shown in Figure 2(a). Thus, when the injection valve opens, the high-pressure hydrogen begins to flow down the 17-mm-long injector tube, forcing out a jet of nitrogen that was at rest in the tube. After expelling all the nitrogen, the hydrogen begins flowing from the tube, and gradually builds up to full pressure. The relative response of the schlieren to the initial jet of nitrogen and then to the hydrogen is unknown, but it is clear from the experimental profiles that the initial jet velocity measured by the schlieren photographs was characteristic of a lower pressure than later experimental profiles. In an attempt to account for the gradual buildup to the full injection pressure, all the experimental profiles were shifted by $-0.3 \mathrm{~ms}$ from the measured times, assuming the transit of the hydrogen jet through the 17-mm-long tip and the buildup to full injection pressure required about $0.3 \mathrm{~ms}$. The predicted penetration rates were greater than the measured rates, but the agreement was better for the higher pressure injections (3.04 MPa and 3.82 $\mathrm{MPa}$ ) than for lower pressure injections (1.86 MPa and 2.45 MPa). Perhaps the higher-pressureinjection cases had less delay times in transiting the $17-\mathrm{mm}$ tube and reaching full injection pressure. These calculations were again based on the $22^{\circ}$ cone angle for the straight tip.

\section{Discussion}

This project has allowed an opportunity to apply the JETMIX model to fuel-air mixing where the fuel concentration can be measured. The model was developed for diesel fuel injection, where the fuel concentration is much more difficult to measure. Therefore, this is an interesting problem. Of course, there are many differences in the injection technology used for diesel fuel and for hydrogen fuel, and some of the special aspects of injecting a compressible gas rather than an incompressible fuel are not handled by the standard JETMIX model.

The JETMIX model was useful in predicting the hydrogen jet behavior, although there were significant differences between the predicted and experimental profiles for hydrogen concentration and hydrogen jet penetration. Certain assumptions were made in both the experimental and computational work that would need to be investigated further to determine the reasons for the differences. For example, the experimental measurements of hydrogen concentration rely on the assumption that the high-velocity jet has the same molecular density, and therefore pressure, as the static bomb. The computational work had to use assumptions about the rearrangement of the hydrogen jet profile from plug flow within the injector tip to a roughly Gaussian profile outside the tip. Also, the computations ignored losses associated with shock waves as the hydrogen jet mixed with nitrogen. Further investigation of all these experimental and computational assumptions is beyond the scope of this project.

Figure 1 illustrates why the use of spark plugs to ignite the hydrogen fuel-air mixture on the edge of a direct-injected hydrogen jet is so difficult. The gradients of fuel concentration are very high, so that in spite of the wide flammability range of hydrogen-air mixtures, it is difficult to assure that the spark plug is located in a flammable mixture. That is, the center of the jet is much too rich to bum, outside the jet is too lean, and the region that contains the proper range of fuel and air to bum is extremely narrow. Further, as in-cylinder air motion such as swirl changes with engine speed or load, the fuel plume may be deflected such that the spark is no longer located in a flammable region.

By going downstream from the injector, the gradients in fuel-air ratio are less severe, providing a larger area in which to locate a spark plug. However, the farther away from the injector the spark plug is located, the more the plume can bend because of swirl in the chamber. A more important objection to moving the spark plug further from the injector tip is that more hydrogen fuel would have to be injected into the chamber before reaching the spark plug, and the high flame speeds of hydrogen generally lead to erratic combustion. 
There appear to be at least two approaches to resolving the problems associated with spark plug location and spark timing in the direct-injection hydrogen engine. One approach is to reduce the flame speed of the hydrogen-air mixture, at least at the time of the spark. The second is to very rapidly mix the hydrogen and air to a combustible mixture over a broader region than is currently available.

There are several potential approaches to reducing the extremely high flame speed of the hydrogen-air mixture. The flame speed of hydrogen is particularly high at conditions well rich of stoichiometric, peaking at $\Phi \approx 1.8$ (excess air ratio $\approx 0.55$ ), and dropping off rapidly for fuel-lean mixtures (Glassman 1987). If a pre-mixed hydrogen-air mixture could be direct-injected at about $\Phi=0.7$ (excess air ratio $=$ 1.4), the peak flame speed would be reduced by about a factor of 4 (relative to a $\Phi=1.8$ mixture). This would allow high power to be achieved when required, but might provide more stable ignition and combustion by avoiding the rich mixtures and high flame speeds. Two possible disadvantages of this approach are that it requires a very high-pressure supply of air and the mixture is then at a flammable mixture ratio in the injection equipment.

Another approach to reducing the flame speed would be to use early-cycle pilot injection to provide a homogenous fuel-lean charge in the cylinder at an equivalence ratio $\Phi$ of about 0.2 (excess air ratio of 5). The charge is ignited by the spark plug, and the hydrogen is direct-injected into the already burning mixture. Pilot injection would provide the energy required for low-power operation, and the directinjected hydrogen would be used at higher power levels. A variation of this approach was recently used by Koyanagi et al. (1993) in which hydrogen was pre-mixed with air outside the cylinder at $\Phi=0.2$. They obtained excellent results in terms of stable combustion and low $\mathrm{NO}_{\mathrm{x}}$ emissions. Early-cycle pilot injection of a small amount of hydrogen might have some safety advantages compared with using premixed gases outside the cylinder.

It might also be possible to use a rich prechamber and lean main chamber as in some natural gas engines. In this case, a small prechamber with a spark plug is used with a very rich mixture of hydrogen. The flame speed is low, but still in the combustible range. Hydrogen is direct-injected into this pilot chamber, and a small amount of air enters the chamber after the fuel is injected. The spark-ignited rich mixture propagates a flame out of the pilot chamber and into the main chamber, which contains a lean premixed hydrogen-air charge. This approach is used for $\mathrm{NO}_{\mathrm{x}}$ control in a number of natural gas engines (e.g., Ajax-Superior).

A conventional approach to reducing flame speeds is to use exhaust gas recirculation (EGR) gases. This has been done with some success by Ninomiya and Furuhama (1992) to reduce $\mathrm{NO}_{\mathrm{x}}$ in hydrogen-fueled spark-ignition engines. EGR in hydrogen engines has the advantage of never containing soot materials that cause problems in some hydrocarbon-fueled engines.

The second approach to avoiding the sensitivity to spark-plug location would to rapidly pre-mix a combustible hydrogen-air mixture close to the injector. One method would be to position the spark plug so that the ground lead always faces up into the hydrogen plume, forming a recirculation zone downstream of the ground lead, right at the spark plug location. This should provide a broader region of well-mixed gases and also help stabilize the flame near the spark plug. The size of the ground electrode might be increased to try to enhance the mixing. A potential disadvantage of any engine with the spark plug close to the fuel injector is reduced spark plug lifetime because of thermal stress.

\section{Summary and Conclusions}

An essential part of this effort was for SwRI personnel to become familiar with the progress made in hydrogen fuel use in internal-combustion engines through research conducted at Musashi I.T. over the past 
20 or more years. Visits by SwRI personnel to Musashi I.T., and vice versa, accomplished the goal of sharing experience with hydrogen fuels.

The general shape of the hydrogen-air (actually hydrogen-nitrogen) mixing as measured by Rayleigh lightscattering measurements was predicted by the JETMIX model, including both axial and radial variations. However, the modeled predictions of hydrogen concentration were greater than the measured values, and the width of the computed hydrogen-nitrogen plume based on schlieren photography was greater than the width measured by Rayleigh light scattering. These observations indicate that either the model or the experiments are not properly conserving mass. The experimental measurements of hydrogen concentration suggest a significantly narrower jet than the width inferred from the schlieren photographs. There are also transient effects of the hydrogen jet propagation through the 17-mm distance between the injector valve and injector tip that are not handled properly in the JETMIX model, which was developed for a diesel-type injector where the valve is very close to the injector tip.

A number of suggestions have been developed during this study to address the extreme sensitivity of the spark-ignition event in hydrogen-fueled engines. Some of these suggestions may be implemented in future engine tests.

\section{Recommendations for Future Work}

Hydrogen offers promise as a fuel that does not produce greenhouse gases. Production, storage, and combustion of hydrogen provides numerous interesting research opportunities. The rough ignition of hydrogen in a spark-ignition engine is a problem observed at Musashi I.T. in Tokyo. SwRI has observed the same rough ignition of hydrogen at some conditions in a diesel-fuel, pilot-ignited, direct-injected, hydrogen-fueled engine. The high flame speeds of hydrogen present unique challenges to the combustion scientist. The discussion above outlined a number of approaches to addressing the rough ignition of hydrogen-fueled engines. 


\section{References}

Furuhama, S. and Tomisawa, N. (1991). "The Power System of a Computer Controlled Hydrogen Car $\mathrm{GH}_{2}$ Injection and Spark Ignition Engine with $\mathrm{LH}_{2}$ Tank and Pump," IMechE C430/028.

Furuhama, S. (1991). "Hydrogen Engine Technology, 'R\&D at Musashi I.T.,'" Project Hydrogen '91 Conference Proceedings of I.A.H.E., p. 161-172.

Furuhama, S. (January, 1992). "Trend of Social Requirements and Technological Development of Hydrogen-Fueled Automobiles," ISAE Review, Vol. 13, No. 1.

Glassman, I. (1987). Combustion, New York: Academic Press, Inc. p. 137.

Heywood, J.B. (1988). Internal Combustion Engine Fundamentals, New York: McGraw-Hill Publishing Co.

Koyanagi, K., Hiruma, M., Hashimoto, H., Yamane, K., and Furuhama, S. (1993). "Low NOx Emission Automobile Liquid Hydrogen Engine by Means of Dual Mixture Preparation," SAE 930757, Warrendale, PA: Society of Automotive Engineers.

Ninomiya, S., and S. Furuhama (1992). "NOx Control in LH2-Pump High Pressure Hydrogen Injection Engines," Proceedings of the 9th World Hydrogen Energy Conference, Paris, France, Vol. 2, p. 1295-1304.

Shapiro, A.S. (1953). The Dynamics and Thermodynamics of Compressible Fluid Flow, Volume I, New York: The Ronald Press Company. 


\section{Appendix A}

\section{Equations for Conservation of Jet Momentum Rate and Fuel Mass Flux in Free Jet and Wall Jet}

This appendix documents the development of the equations used in the jet mixing model for the free jet and the wall jet. Because the application in this project was limited to the free jet close to the injector, the wall jet portion of the code was not used.

The derivation of the equations for conservation of jet momentum rate and fuel mass flux follows that of Sinnamon et al. (1980), except that a constant cone angle is assumed (Melton 1971) rather than the assumptions about entrainment rate used by Sinnamon et al. This was for ease in adapting the model for the wall jet, where the spreading angles are presumably easier to measure than the entrainment rate. Another exception to the approach by Sinnamon et al. is that the effect of swirl on the trajectory of the free jet is not included in the calculations reported here. The effect of swirl on entrainment rate is included both in this model and in the model by Sinnamon et al. Please see Sinnamon et al. (1980) for a more thorough discussion of the development of a similar set of equations.

Three assumptions commonly used in the analysis of jets were used to derive the equations used in this model:

(1) The fuel mass-flow rate of the jet at every axial cross-section is the same, and is equal to the fuel mass flow rate at the source.

(2) The momentum rate of the jet at every cross-section is the same, and is equal to the momentum rate of the jet at the source.

(3) The spreading angle of the jet is assumed to be constant, and the profiles of velocity and fuel mass fraction are assumed to be self-similar and to follow the profiles described below.

\section{Flow Chart}

A flow chart of the model as currently configured is as follows:

A. Description of program

B. Definitions

C. Input

1. Fixed input

2. Keyboard input

3. File input

D. Cone angle calculation

1. Hiroyasu correlation for cone angle.

2. Calculate half-angle from centerline to $1 / 2$ velocity point.

3. Calculate radius of free jet at piston bowl wall. 
E. Calculate orifice discharge coefficient, exit velocity, fuel mass flow rate, and momentum rate of the source of the jet.

F. Jet breakup calculations (not used except for comparison purposes)

1. Breakup time and distance according to Yule et al.

2. Breakup time and distance according to Sinnamon et al.

G. Calculate jet fuel concentration, density, and velocity at all radial locations at a given axial location. Repeat all items in $G$ until final axial distance is reached.

1. Guess large initial value for centerline fuel mass fraction.

2. Has jet reached the wall at this axial location?

a. Yes - go to G.5.

b. No - go to G.3.

H. Free jet. Calculate integrals for fuel mass flux conservation and momentum rate conservation, and corresponding centerline jet velocities for free jet from each of these conservation equations.

1. Does centerline free jet velocity computed from fuel mass flux conservation approx. equal jet velocity from momentum rate conservation?

a. Yes - go to G.8.

b. No - decrease guess for centerline fuel fraction and go to G.3.

2. If this is first time at this step, guess large initial value for centerline fuel mass fraction for wall jet. Otherwise, initial guess is previous value from converged solution for next earlier axial location.

3. Wall jet. Calculate integrals for fuel mass flux conservation and momentum rate conservation, and corresponding centerline jet velocities for wall jet for each of these conservation equations.

4. Does centerline wall jet velocity computed from fuel mass flux conservation approx. equal jet velocity from momentum rate conservation?

a. $\quad$ Yes - go to G.8.

b. $\quad$ No - decrease guess for centerline fuel mass fraction and go to G.6.

5. Limit jet velocity to that measured by Arai et al. Calculate transit time and average velocity between axial locations.

6. Calculate fuel mass flux at axial location from conservation of fuel mass flux for free jet or wall jet as appropriate.

7. Calculate total amount of fuel injected to time T(I) from: (a) the mass flow rate through the injector hole, and (b) from summing up the mass flux at each axial location. Compare these two for check of computation of (b).

8. Write penetration data (time, axial distance for free jet and wall jet, centerline velocity, and centerline fuel concentration).

9. Increment axial location and check to see if beyond final axial location.
a. Yes - go to $\mathrm{H}$.
b. No - go to G.2.

I. Starting at first axial location, and continuing to final axial location, determine the fuel-air equivalence ratio $(\Phi)$ at each radial location.

1. Calculate the half width of the jet to the $1 / 2$ velocity point.

2. Calculate the width of the jet to zero velocity point, and divide into JMAX number of equal radial locations.

3. Calculate the fuel mass fraction and jet velocity at each radial location for JMAX locations at one axial location. 
4. For a given axial location and radial location, calculate the fuel mass flow rate through an annulus of width B/JMAX from the conservation of fuel mass flux equation. Use the equation for a free jet or wall jet as appropriate for the axial location.

5. Sum fuel mass flow rates through all annuli to get total fuel flow rate at an axial location.

6. Multiply total fuel mass flow rate integrated over all radial locations at one axial location by transit time for jet centerline between axial locations to compute mass of fuel in jet between axial locations XC(I-1) and XC(I).

7. Determine fuel-air ratio and equivalence ratio at each radial location for a given axial location.

8. Write out plot file for contours of equivalence ratio $(\Phi)$.

9. Form sums that represent the mass of fuel in equivalence ratio bands " $K$ " at a given axial location I.

10. Update radial location and check to see if all radial locations have been calculated.

a. Yes - go to H.11.

b. No - go to H.3.

11. Update axial location and check to see if all axial locations have been calculated

a. Yes - go to I.

b. No - go to H.1.

J. Sum up the mass of fuel in equiv. ratio band "K" over axial locations $I=1$ to IX where IX varies from $\mathrm{I}=1$ to XSTEPM, the total number of axial steps.

1. Write file name corresponding to axial step IX

2. Determine cumulative fuel mass at equiv. ratio " $K$ " for all axial locations from $I=1$ to $I X$.

3. Smooth the cumulative fuel mass values (MASFPC(K)) using 3 pt. to 5 pt. smoothing routine.

4. Normalize the cumulative fuel mass values at each equiv. ratio by the width of the equiv. ratio bands.

5. Write equiv. ratio band center (PHIX(KK)) and normalized cumulative fuel mass in that equiv. ratio band summed over axial locations $\mathrm{I}=1$ to $\mathrm{IX}$ to output file.

6. Check for mass conservation.

7. Update axial location IX to next axial location. Check to see if $\mathrm{XX}$ is at final location XSTEPM.
a. Yes - go to $\mathrm{K}$.
b. No - go to J.1.

K. End

L. Functions

1. Function DISCHR. Calculate discharge coeff. of injector orifice.

M. Subroutines

1. Subroutine XI21. Calculate integral I21, for free jet momentum rate conservation.

2. Subroutine XI33. Calculate integral I33, for free jet fuel mass flux conservation.

3. Subroutine XI41. Calculate integral I41, for wall jet momentum rate conservation.

4. Subroutine XI42. Calculate integral I42, for wall jet fuel mass flux conservation.

5. Subroutine AIRDEN. Calculate air density, piston location, cylinder volume, etc. as a function of crank angle. (Not currently used.)

6. Subroutine CYCLE. Calculate bulk gas temperature from cycle simulation. (Not currently implemented.) 


\section{Mathematical Development of JETMIX Model}

The jet velocity profile is described by

$$
u=u_{m}[f(\varepsilon)]^{2}
$$

where $u$ is the local jet velocity, $u_{m}$ is the centerline jet velocity at a given axial location, $f(\varepsilon)=1 .-\varepsilon^{1.5}$, and $\varepsilon=r / b$, where $r$ is the local radius and $b$ is the radius of the jet from the centerline to the point where the velocity is zero. The fuel mass fraction profile is similar to the velocity profile but slightly broader. The fuel mass fraction at any radial location, $c$, is described as

$$
c=c_{m} f(\epsilon)
$$

where $c_{m}$ is the centerline fuel mass fraction and $f(\varepsilon)$ is the same as above. These profiles are shown in Figure A-1.

\section{Free Jet Analysis}

For the free jet, the conservation of fuel mass flow rate called for in assumption (1) above may be written (Sinnamon et al. 1980),

$$
\frac{d}{d x}\left[\int c \rho u d A\right]=0
$$

where $\mathrm{x}$ is the axial distance, $\mathrm{c}$ is local fuel mass fraction, $\rho$ is the local jet density, $\mathrm{u}$ is the local velocity, and $A$ is the cross-sectional area of the jet. Defining $\beta=1-\rho_{\infty} / \rho_{f}$, where $\rho_{\infty}$ is the density of the air or gases in the chamber, and $\rho_{\mathrm{f}}$ is the density of the fuel, then the local density $\rho$ is related to the fuel mass fraction $\mathrm{c}$ by,

$$
\rho=\frac{\rho_{\infty}}{1-c\left(1-\rho_{\infty} / \rho_{f}\right)}
$$

The cross-sectional area of the free jet is related to the local radius $r$ and the non-dimensional radius $\varepsilon$ by

$$
A=\pi r^{2}=\pi b^{2} \varepsilon^{2}
$$

and the differential area is then

$$
\mathrm{dA}=2 \pi \mathrm{b}^{2} \varepsilon \mathrm{d} \varepsilon
$$

Substituting Eqs. (1), (2), (4), and (6) into (3),

$$
\frac{d}{d x}\left[2 \pi b^{2} \rho_{\infty} u_{m} c_{m} \int_{0}^{1} \frac{f(\varepsilon)^{3} \varepsilon}{1-\beta c_{m} f(\varepsilon)} d \varepsilon\right]=0
$$




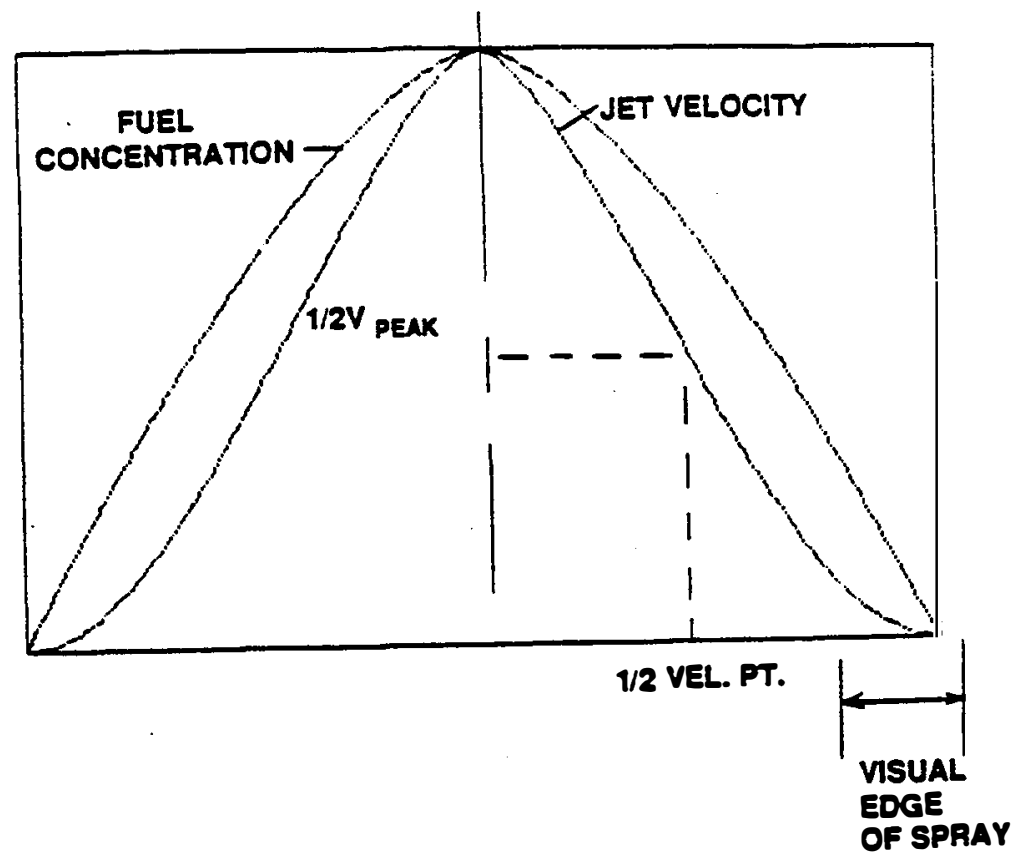

Figure A-1. Radial distribution of fuel jet velocity and fuel mass concentration.

Now at the jet source (the exit from the hole), the fuel mass flow rate is just

$$
\dot{\mathrm{m}}=\rho_{\mathrm{f}} \mathrm{u}_{\mathrm{s}} \mathrm{A}_{\mathrm{s}}
$$

where the subscripts $s$ refer to those values at the source. The initial jet velocity, $u_{s}$, is just

$$
u_{s}=c_{D} \sqrt{\frac{2 \Delta P_{i n j}}{\rho_{f}}}
$$

where $c_{d}$ is the discharge coefficient of the injector hole and $\Delta P_{i n j}$ is the differential injection pressure. The injector hole area $A_{s}$ is

$$
A_{s}=\pi d^{2} / 4
$$

Therefore the fuel mass flow rate at the source is

$$
\dot{\mathrm{m}}_{\mathrm{s}}=\pi \mathrm{d}^{2} \rho_{\mathrm{f}} \mathrm{c}_{\mathrm{D}} \sqrt{2 \Delta \mathrm{P}_{\mathrm{inj}} / \rho_{\mathrm{f}}} / 4
$$

but from assumption 1 and Eq. (3), $m=m_{s}$, so Eq. (7) is just equal to 11 , or,

$$
2 \pi b^{2} \rho_{\infty} u_{m} c_{m} \int_{0}^{1} \frac{f(\varepsilon)^{3} \varepsilon}{1-\beta c_{m} f(\varepsilon)} d \varepsilon=\pi \rho_{f} c_{D} \sqrt{2 \Delta P_{i n j} / \rho_{f}} d^{2} / 4
$$


Equation (12) represents the conservation of fuel mass flux for the free jet at every cross-section. There are two unknowns in Eq. (12), the centerline velocity at a given axial location, $u_{m}$, and the centerline fuel fraction, $c_{m}$. By developing the equation for conservation of jet momentum rate of the free jet in terms of the same two unknowns, the two equations may be solved simultaneously to determine the two unknowns. Once the centerline values of velocity and fuel mass fraction are determined at every axial location, the radial profiles may be determined from Eq. (1) and (2).

The conservation of momentum rate of the free jet may be expressed as (Sinnamon et al. 1980)

$$
\frac{d}{d x}\left[\int \rho u^{2} d A\right]=0
$$

This may be rewritten by making substitutions in the same manner as above to obtain

$$
\frac{\mathrm{d}}{\mathrm{dx}}\left[2 \pi \mathrm{b}^{2} \rho_{\infty} \mathrm{u}_{\mathrm{m}}^{2} \int_{0}^{1} \frac{\mathrm{f}(\varepsilon)^{4} \varepsilon}{1-\beta \mathrm{c}_{\mathrm{m}} \mathrm{f}(\varepsilon)} \mathrm{d} \varepsilon\right]=0
$$

Now the momentum rate at the source is just

$$
i_{s}=\pi \rho_{f} u_{s}^{2} d^{2} / 4
$$

and from Eq. (14), this must be equal to the jet momentum rate at every cross-section downstream, or

$$
2 \pi b^{2} \rho_{\infty} u_{m}^{2} \int_{0}^{1} \frac{f(\varepsilon)^{4} \varepsilon}{1-\beta c_{m} f(\varepsilon)} d \varepsilon=\pi \rho_{f}\left(c_{D}^{2} 2 \Delta P / \rho_{f}\right) d^{2} / 4
$$

Equation (16) may be solved simultaneously with Eq. (12) to determine the two unknowns, $u_{m}$ and $c_{m}$. Because $c_{m}$ is included in integral expressions in both Eqs. (12) and (16), it is most practical to solve these equations numerically. That is the procedure used in this computer code. Thus, at a given axial location, a large initial value is assumed for $c_{m}$ and both Eqs. (12) and (16) are solved for $u_{m}$, and a check is made to determine if they are approximately equal. If they are not equal, the guess for $\mathrm{c}_{\mathrm{m}}$ is decreased and the process is repeated until the values for $\mathrm{u}_{\mathrm{m}}$ are approximately equal. This procedure is repeated for each axial location from close to the jet source to a full set of downstream locations. The first initial guess for $c_{m}$ close to the injector is taken as 0.998 , and then the guessed values for $c_{m}$ are decreased until the $u_{m}$ values are approximately equal. At the next axial location, the initial value for $c_{m}$ is taken as the final value from the previous axial location, and then decreased until the $u_{m}$ values from the two equations are again approximately equal. This is based on the assumption that the centerline fuel fraction $c_{m}$ is constantly decreasing as the axial distance increases. The only exception to this is for the first step after the jet has reached the wall, where the initial guess for $\mathrm{c}_{\mathrm{m}}$ is again taken as 0.998 .

\section{Wall Jet Analysis}

The treatment of the fuel jet behavior after it hits the wall has not been treated in the literature in a similar manner to that of the free jet. However, there is literature describing the impingement of gas jets with walls (e.g., Poreh et al. 1967; Beltaos and Rajaratnam 1977; Iida et al. 1990), and this is being used to 
improve the wall jet model. There is also literature describing the interaction of a two-phase jet with a wall, but that is not pertinent to this discussion.

The initial approach used here in treating the wall jet is to make similar assumptions to those used in the free jet with adjustments made to the geometry. In fact, the three assumptions listed above for the free jet were assumed to hold true for the wall jet, and the profiles of velocity and fuel mass fraction were assumed to be the same as for the free jet, with the centerline values now assigned to the streamlines next to the wall, and with velocity and fuel mass fraction decreasing in the direction away from the wall. This approach ignores the friction of the wall, and the resulting boundary layer next to the wall. Also the initial effort assumes impingement at normal incidence, although impingement at other angles will have to treated in the future.

The wall geometry is assumed to follow that shown in Figure A-2, with the axial coordinate $x$ ' representing the distance along the wall and the radial coordinate $r$ ' now representing the distance away from the wall. The area of the annulus representing the jet at a given axial location $x^{\prime}$ is

$$
A=\pi x^{\prime}\left(r_{I}+r^{\prime}\right)
$$

and since $r^{\prime}=b^{\prime} \varepsilon^{\prime}$, where $b^{\prime}$ is the distance from the wall to the edge of the wall jet and $\varepsilon^{\prime}=r^{\prime} / b^{\prime}$, then the wall jet area can be written as

$$
\mathrm{A}=\pi \mathrm{x}^{\prime}\left(\mathrm{b}^{\prime} \varepsilon^{\prime}+\mathrm{r}_{\mathrm{I}}\right)
$$

and the differential written as

$$
\mathrm{dA}=\pi \mathrm{x}^{\prime} \mathrm{b}^{\prime} \mathrm{d} \varepsilon^{\prime}
$$

The conservation of the fuel mass flux of the wall jet is the same as the free jet in general terms, i.e., Eq. (3), except that the initial upper limit of integration is $\varepsilon^{\prime}=r_{I} / b^{\prime}$, where $r_{1}$ is the distance from the maximum velocity point in the wall jet to the zero velocity point.

$$
\frac{\mathrm{d}}{\mathrm{dx}}\left[\int \operatorname{coudA}\right]=0
$$

but the values suitable for the wall jet must be substituted giving

$$
\frac{d}{d x^{\prime}}\left[\int\left(c_{m} f\left(\varepsilon^{\prime}\right)\right)\left(\frac{\rho_{\infty}}{1-\beta c_{m} f\left(\varepsilon^{\prime}\right)}\right)\left(u_{m} f\left(\varepsilon^{\prime}\right)^{2}\right)\left(\pi x^{\prime} b^{\prime} d \varepsilon^{\prime}\right)\right]=0
$$

or pulling out the constant terms to get

$$
\frac{\mathrm{d}}{\mathrm{dx}{ }^{\prime}}\left[\pi \mathrm{c}_{\mathrm{m}} \rho_{\infty} \mathrm{x}^{\prime} \mathrm{b}^{\prime} \int_{0}^{1} \frac{\mathrm{f}\left(\varepsilon^{\prime}\right)^{3}}{1-\beta \mathrm{c}_{\mathrm{m}} \mathrm{f}\left(\varepsilon^{\prime}\right)} \mathrm{d} \varepsilon^{\prime}\right]=0
$$


WALL IMPINGEMENT -

MODEL ASSUMPTIONS

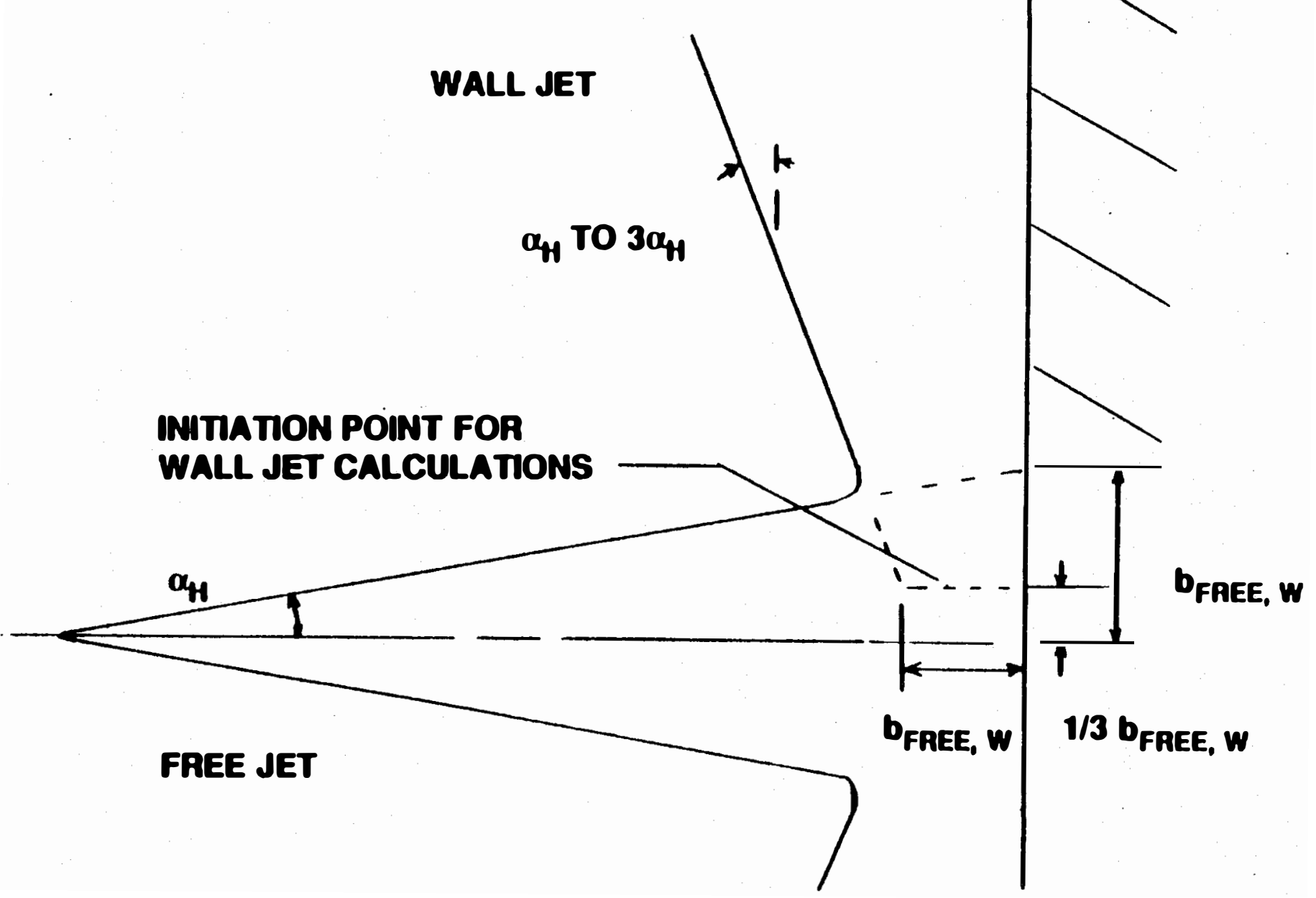

Figure A-2. Schematic of free-jet impingement with wall, and creation of wall jet. 
Equating the mass flux at any cross-section to that at the source

$$
\pi c_{m} \rho_{\infty} u_{m} x^{\prime} b^{\prime} \int_{0}^{1} \frac{f\left(\varepsilon^{\prime}\right)^{3}}{1-\beta c_{m} f\left(\varepsilon^{\prime}\right)} d \varepsilon^{\prime}=\pi \rho_{f} c_{D} \sqrt{2 \Delta P_{i n j} / \rho_{f}} d^{2} / 4
$$

so that in a similar way to the free jet, Eq. (23) represents the conservation of fuel mass flux and provides one equation with two unknowns, the "centerline" velocity, $u_{m}$, in this case the velocity just outside the boundary layer at the wall, and the "centerline" fuel mass fraction, $c_{m}$, defined at the same point. Again adding the equation for jet momentum rate conservation allows the opportunity to solve simultaneous equations to determine the two unknowns.

The conservation of momentum rate for the wall jet is the same in general terms as for the free jet,

$$
\frac{\mathrm{d}}{\mathrm{dx}}\left[\int \rho \mathrm{u}^{2} \mathrm{dA}\right]=0
$$

Substituting the appropriate values for the wall and simplifying gives,

$$
\frac{\mathrm{d}}{\mathrm{dx}}\left[\pi \mathrm{x}^{\prime} \mathrm{b}^{\prime} \rho_{\infty} \mathrm{u}_{\mathrm{m}}^{2} \int_{0}^{1} \frac{\mathrm{f}\left(\varepsilon^{\prime}\right)^{4}}{1-\beta \mathrm{c}_{\mathrm{m}} \mathrm{f}\left(\varepsilon^{\prime}\right)} \mathrm{d} \varepsilon^{\prime}\right]=0
$$

Because the jet momentum rate is conserved, the jet momentum rate at any distance along the wall is equal to the momentum rate of the source, which is given by Eq. (15), so

$$
\pi x^{\prime} b^{\prime} \rho_{\infty} u_{m}^{2} \int_{0}^{1} \frac{f\left(\varepsilon^{\prime}\right)^{4}}{1-\beta c_{m} f\left(\varepsilon^{\prime}\right)} d \varepsilon^{\prime}=\pi \rho_{f}\left(c_{D}^{2} 2 \Delta P_{i n j} / \rho_{f}\right) d^{2} / 4
$$

Equations (23) and (26) are solved simultaneously using the same numerical procedure as described above for the free jet.

The solution of the free jet and wall jet equations are independent of each other. The actual process between a free jet and a wall jet involves a complicated transition region that is not modeled using this approach. However, solving the free jet and wall jet independently requires that initial conditions be established for the wall jet that may depend on the free jet. The best approximation for the initial conditions of the wall jet are currently under study. The calculations performed to date have assumed that the initial height of the wall jet in a direction at right angles to the wall is identical to the calculated radius that the free jet at an axial location corresponding to the wall. This is illustrated in Figure A-2. The initial location of the wall jet was assumed to be $1 / 3$ of the way out from the centerline to the full jet width at the wall, as shown in Figure A-2. This may be stated in words that the free jet is assumed to approach the wall and then open up uniformly at the wall with the maximum jet velocity close to the wall, with decreasing velocity going outward from the wall.

The analysis by Poreh et al. (1967) suggests that the initial height of the wall jet is much less than that assumed for the calculations shown in this report. Thus, the initial conditions of the wall jet will probably be changed, but a more thorough review of the literature is required before this change is made in the model. 


\section{References}

Arai, M., Tabata, M. Hiroyasu, H., and Shimizu, M. (1984). "Disintegrating Process and Spray Characterization of Fuel Jet Injected by a Diesel Nozzle," SAE Transactions, Vol. 93, and SAE Paper No. 840275.

Beltaos, S., and Rajaratnam, N. (1977). "Impingement of Axisymmetric Developing Jets," Journal of Hydraulic Research, Volume 15, No. 4, pp. 311-325.

Iida, N., Hirawo, K., and Sato, G. T. (1990). "Experimental Study of Transient Gas Jet Impinging on a Wall," SAE Paper No. 900479.

Melton, R.B., Jr. (1971). "Diesel Fuel Injection Viewed as a Jet Phenomena," SAE Paper No. 710132.

Poreh, M., Tsuei, Y.G., and Cermak, J.E. (1967). "Investigation of a Turbulent Radial Wall Jet," Journal of Applied Mechanics, pp. 457-463.

Sinnamon, J.F., Lancaster, D.R., and Stiener, J.C. (1980). "An Experimental and Analytical Study of Engine Fuel Spray Trajectories," SAE Paper No. 800135.

Yule, A.J., Mirza, M.R., and Filipovic, I. (1991). "Correlations for Diesel Spray Penetration including the Effects of the Break-Up Zone," Proceedings of the Fifth International Conference on Liquid Atomizaiton and Spray Systems," H.G. Semerjian, editor, pp. 267-274. 


\section{Nomenclature}

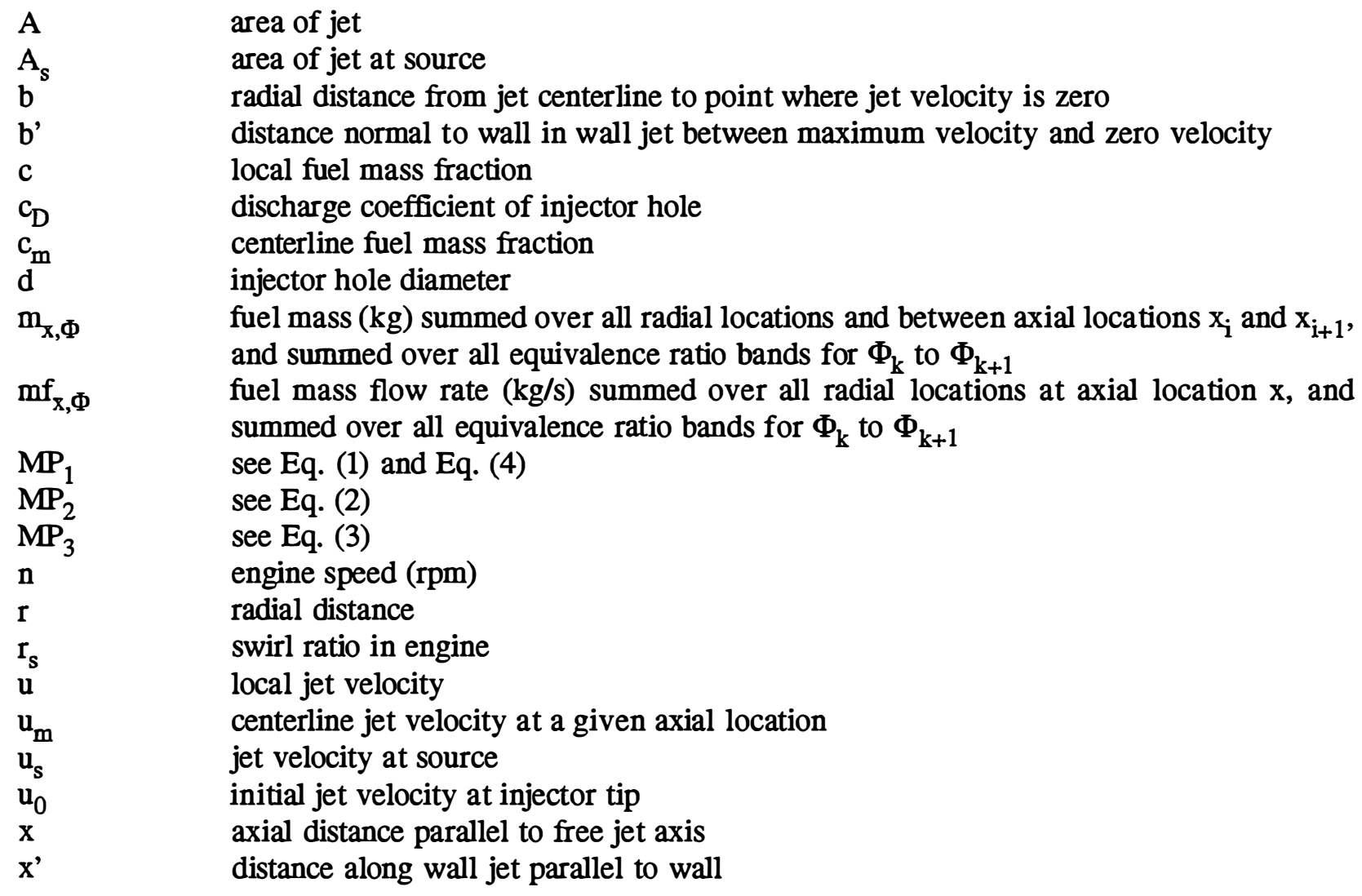

\section{Greek Symbols}

$\begin{array}{ll}\mathbf{6} & 1-\rho_{\infty} / \rho_{\mathrm{f}} \\ \Delta \mathrm{P}_{\mathrm{inj}} & \text { pressure differential across injector hole } \\ \varepsilon & \text { normalized radial distance from centerline of free jet, r/b } \\ \varepsilon & \text { normalized distance normal to wall from maximum velocity point in wall jet, } \mathrm{r}^{\prime} / \mathrm{b}^{\prime} \\ \theta & \text { spray cone angle, without swirl, between visual edges of spray } \\ \Theta_{\mathrm{s}} & \text { spray cone angle with swirl } \\ \rho & \text { local jet density } \\ \rho_{\mathrm{f}} & \text { density of the liquid fuel } \\ \rho_{\infty} & \text { density of air or gases in chamber } \\ \Phi & \text { equivalence ratio, or (fuel/air) actual / (fuel/air) } \text { stoichiometric } \# 1, \mathrm{MP}_{1} \\ \Phi_{1} & \text { equivalence ratio limit associated with mixing parameter } \# 1, \mathrm{MP}_{2} \\ \Phi_{2} & \text { equivalence ratio limit associated with mixing parameter \#2, } \mathbf{M P}_{3} \\ \Phi_{3} & \text { equivalence ratio limit associated with mixing parameter \#3, } \mathrm{MP}_{3} \\ \Phi_{\mathrm{k}} & \text { equivalence ratio for the kth equivalence ratio band }\end{array}$




\section{REPORT DOCUMENTATION PAGE}

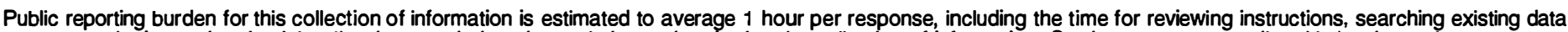

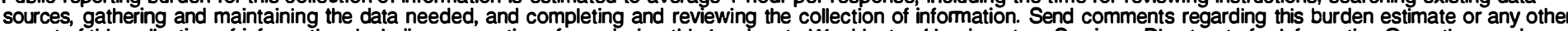

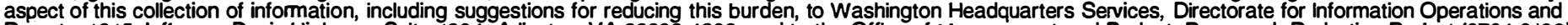

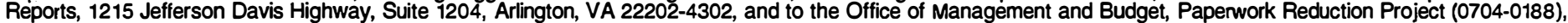
Washington, DC 20503
1. AGENCY USE ONLY (Leave blank)
2. REPORT DATE
3. REPORT TYPE AND DATES COVERED
June 1994
Subcontract report

\section{TITLE AND SUBTITLE}

Hydrogen-Air Mixing Evaluation in Reciprocating Engines

5. FUNDING NUMBERS

(C) AW-2-12266-1

(TA) FU421010

6. $\operatorname{AUTHOR}(S)$

L. Dodge and D. Naegeli

7. PERFORMING ORGANIZATION NAME(S) AND ADDRESS(ES)

Southwest Research Institute

San Antonio, Texas 78228-0510

8. PERFORMING ORGANIZATION REPORT NUMBER

DE94006950

9. SPONSORING/MONITORING AGENCY NAME(S) AND ADDRESS(ES)

National Renewable Energy Laboratory

1617 Cole Boulevard

Golden, CO 80401-3393

10. SPONSORING/MONITORING

AGENCY REPORT NUMBER

NRELTP-425-6346

\section{SUPPLEMENTARY NOTES}

12a. DISTRIBUTION/AVAILABILITY STATEMENT

National Technical Information Service

U.S. Department of Commerce

5285 Port Royal Road

Springfield, VA 22161

\section{ABSTRACT (Maximum 200 words)}

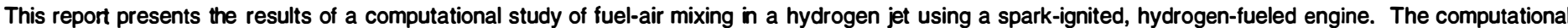

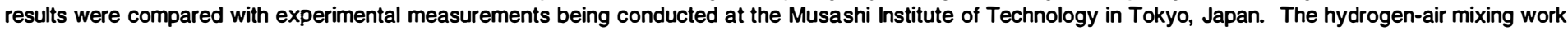
was directed at understanding the extreme sensitivity of ignition to spark plug location and spark timing in direct-injected, hydrogen-fueled engines.

\section{SUBJECT TERMS}

Hydrogen fuel, hydrogen-fueled engines, hydrogen-air mixing

17. SECURITY CLASSIFICATION
OF REPORT

18. SECURITY CLASSIFICATION OF THIS PAGE 12b. DISTRIBUTION CODE

UC-335
NSN 7540-01-280-5500 Prescribed by ANSI Std. Z39- 